\title{
Thalamic Control of Neocortical Area Formation in Mice
}

\author{
Tou Yia Vue, ${ }^{1,2 \star}$ Melody Lee, ${ }^{1 \star}$ Yew Ei Tan, ${ }^{1}$ Zachary Werkhoven, ${ }^{1}$ Lynn Wang, ${ }^{1}$ and Yasushi Nakagawa ${ }^{1,2}$ \\ ${ }^{1}$ Department of Neuroscience, Developmental Biology Center, Stem Cell Institute, and ${ }^{2}$ Graduate Program in Neuroscience, University of Minnesota, \\ Minneapolis, Minnesota 55455
}

The mammalian neocortex undergoes dramatic transformation during development, from a seemingly homogenous sheet of neuroepithelial cells into a complex structure that is tangentially divided into discrete areas. This process is thought to be controlled by a combination of intrinsic patterning mechanisms within the cortex and afferent axonal projections from the thalamus. However, roles of thalamic afferents in the formation of areas are still poorly understood. In this study, we show that genetically increasing or decreasing the size of the lateral geniculate nucleus of the mouse thalamus resulted in a corresponding change in the size of the primary visual area. Furthermore, elimination of most thalamocortical projections from the outset of their development resulted in altered areal gene expression patterns, particularly in the primary visual and somatosensory areas, where they lost sharp boundaries with adjacent areas. Together, these results demonstrate the critical roles of thalamic afferents in the establishment of neocortical areas.

\section{Introduction}

The neocortex is one of the most complex regions in the mammalian brain, and the formation of functionally and anatomically discrete neocortical areas during development is crucial for our perception, motor control, learning, and memory. Area formation is a multistep process. In early embryonic stages, neuroepithelial and radial glial cells show graded expression patterns of transcription factors regulated by secreted signaling molecules including fibroblast growth factors and Wnt proteins. These transcription factors specify the positional identity of neural progenitor cells and their postmitotic areal fate (O'Leary et al., 2007; Hoch et al., 2009; Rakic et al., 2009; Sansom and Livesey, 2009; Borello and Pierani, 2010).

Later in embryogenesis, topographically organized, afferent axons from the thalamus [thalamocortical axons (TCAs)] reach the cortex and start to invade the cortical plate in their target cortical regions. By the end of the first postnatal week, discrete tangential and laminar gene expression patterns are established in postmitotic neurons, delineating future functional areas in the neocortex. Ablation and transplantation studies have long suggested that TCAs are required for the establishment of area-

Received Dec. 18, 2012; revised March 31, 2013; accepted April 5, 2013.

Author contributions: T.Y.V., M.L., Z.W., and Y.N. designed research; T.Y.V., M.L., Y.E.T., Z.W., L.W., and Y.N. performed research; T.Y.V., M.L., Y.E.T., Z.W., L.W., and Y.N. analyzed data; T.Y.V. and Y.N. wrote the paper.

This study was supported by NINDS Grant R01 NS049357, the Whitehall Foundation, and Wallin Neuroscience Discovery Funds and Autism Initiative Funds from the University of Minnesota, as well as Doctoral Dissertation Fellowship (T.Y.V.) and Undergraduate Research Opportunities Programs (Y.E.T., L.W., and Z.W.) from the University of Minnesota. We thank Geoff Ghose, Glenn Giesler, Paul Letourneau, Steven McLoon, and members of Nakagawa Laboratory for comments and discussion; Dino Leone for advice on immunostaining; Lauren Bolopue, Andrew Hanson, David Scott, and Lyhun Tan for excellent technical assistance; and Yasuhiko Kawakami for Shh ${ }^{N /+}$ and CMV-Cre mice.

${ }^{*}$ T.Y.V. and M.L. contributed equally to this work.

Correspondence should be addressed to Dr. Yasushi Nakagawa, Department of Neuroscience, University of Minnesota, 6-145 Jackson Hall, 321 Church Street SE, Minneapolis, MN 55455. E-mail: nakagawa@umn.edu.

T.Y.Vue's present address: Department of Neuroscience, University of Texas Southwestern Medical Center, 6000 Harry Hines Boulevard, Dallas, TX 75390-9111

DOI:10.1523/JNEUROSCI.5786-12.2013

Copyright $\odot 2013$ the authors $\quad 0270-6474 / 13 / 338442-12 \$ 15.00 / 0$ specific cytoarchitecture (Wise and Jones, 1978; Dehay et al., 1991; Rakic et al., 1991; Schlaggar and O'Leary, 1991; Gitton et al., 1999). However, genetic mutations in mice that cause missing (Miyashita-Lin et al., 1999; Nakagawa et al., 1999) or shifted (Garel et al., 2002) TCA projections did not result in major changes in gene expression patterns in the cortical plate at late embryonic or neonatal stages. These studies suggested that intrinsic patterning mechanisms are predominantly responsible for regionalization of the cortex during embryogenesis. However, these mutant mice died before area boundaries in the neocortex were well defined. Thus, it is currently unknown whether TCAs exert any roles in the establishment of discrete neocortical areas.

To resolve this issue, we genetically altered thalamic neurons from the outset of their axonal projections to the neocortex. Specifically, we generated postnatally viable mutant mice in which, (1) the number of thalamocortical projection neurons was increased or decreased in the principal visual nucleus [dorsal lateral geniculate (dLG)], or (2) almost no TCAs project to the neocortex. These genetic manipulations were specific to the thalamus so that changes observed in the neocortex could be attributed to changes in TCA projections. When we increased or decreased the size and cell number of the dLG nucleus by manipulating Sonic hedgehog (Shh) signaling in thalamic progenitor cells, TCA projections to the primary visual area were expanded or reduced, respectively. These mice still retained clear gene expression boundaries between areas, but the size of the primary visual area was altered in accordance with the change in geniculocortical projections. Furthermore, when TCA projections to the neocortex were nearly eliminated in mice lacking the homeobox gene Gbx2 in the thalamus, gene expression patterns in the neocortex, most evident in the prospective primary sensory areas, were disrupted, leading to less discrete boundaries between prospective sensory areas and their surrounding areas. These findings demonstrate that TCAs play a crucial role in early establishment of area identity in the neocortex. 


\section{Materials and Methods}

Mice

Care and experimentation on mice were done in accordance with the Institutional Animal Care and Use Committee of the University of Minnesota. Noon of the day on which the vaginal plug was found was counted as embryonic day 0.5 (E0.5), and the day of birth was designated as postnatal day $0(\mathrm{P} 0)$. To generate $\mathrm{Olig} 3^{\mathrm{Cre} /+} ; \mathrm{R}_{2} 6^{\text {stopSmoM2/+ }}$ mice, we bred Olig $3^{\mathrm{Cre} /+}$ mice (Vue et al., 2009) with Rosa26 $6^{\text {stopSmoM2/stopSmoM2 }}$ mice (Jeong et al., 2004) (obtained from The Jackson Laboratory), and used $\mathrm{Cre}^{-}$progeny as controls. For conditional deletion of $\mathrm{Sh} h$, we bred Olig $3^{\mathrm{Cre} /+} ; \mathrm{Shh}^{\mathrm{N} /+}$ mice with Shh${ }^{\mathrm{C} / \mathrm{C}}$ mice (Lewis et al., 2001) (obtained from The Jackson Laboratory). All of the non-Olig $3^{\mathrm{Cre} /+} ; \mathrm{Shh}^{\mathrm{N} / \mathrm{C}}$ littermates showed normal phenotypes. For conditional deletion of $G b \times 2$, we bred $\mathrm{Olig}^{\mathrm{Cre} /+}$; Gbx $2^{\mathrm{Cl+}}$ mice with $\mathrm{Gb} \times 2^{\mathrm{ClC}}$ mice (Li et al., 2002) (obtained from The Jackson Laboratory). Only Olig $3^{\mathrm{Cre} /+} ; \mathrm{Gb} \times 2^{\mathrm{ClC}}$ showed detectable phenotypes. We found similar phenotypes in TCA pathfinding in $G b \times 2$ conditional mutants in which a null mutant allele was used in the breeding scheme to generate $\mathrm{Olig} 3^{\mathrm{Cre} /+} ; G b \times 2^{N / C}$ mice. The $G b \times 2^{N}$ allele was produced by germline deletion of $G b \times 2$ exon 2 by breeding $\mathrm{Gb}_{2} 2^{c / c}$ mice and heterozygous $\mathrm{CMV}$-Cre mice. These Olig $3^{\mathrm{Cre} /+}$; $G b \times 2^{N / C}$ mice were used for Fig. $7 M-T$. All mice were kept in C57B/L6 background and embryos or pups of either sex were used.

\section{In situ hybridization and immunostaining}

In situ hybridization and immunostaining were performed based on Vue et al. (2007). In this study, goat anti-Netrin-G1 (R\&D Systems, 1:100), rabbit anti-serotonin (Immunostar, 1:20,000 or Millipore, 1:500), rabbit anti-ROR $\beta$ (Diagenode, 1:100), and goat anti-Lmo4 (Santa Cruz Biotechnology, 1:100) were used. Prenatal brains were cut with a cryostat at $20-35 \mu \mathrm{m}$ thick. Postnatal brains were cut with a sliding microtome at 50 $\mu \mathrm{m}$ thick and the sections were mounted on slides before in situ hybridization or immunostaining was performed. Each set of data shown in Figs. $1 A-H, 3,4,5 A-F, 7 M-T, 8$, and $9 A-F$ were obtained from adjacent sections.

\section{Axon tracing with NeuroVue dyes}

NeuroVue axon tracers (FS-1002 NeuroVue Red, FS-1001 NeuroVue Maroon) were inserted to primary visual area (V1) and primary somatosensory area (S1) of P8 cortex and the brains were incubated in 4\% paraformaldehyde for $\sim 4$ weeks, before sectioning with a vibrating microtome $(150 \mu \mathrm{m})$. Sections were counterstained with bisbenzimide $\mathrm{H}$ 33342 (Sigma-Aldrich).

\section{Quantification}

$d L G$ cell count and size measurement. Each $20 \mu \mathrm{m}$ cryosection was collected and sequentially mounted onto six slides for in situ hybridization analysis of P0 thalamus. Two slides were analyzed for cell count and size measurement and other slides were used for in situ hybridization for $R O R \alpha$. Because some Olig $3^{\mathrm{Cre} /+} ; \mathrm{R}_{2} 6^{\text {stopSmoM2/+ }}$ mice had clustered $\mathrm{ROR} \alpha$ positive areas, the region to be counted or measured as dLG was defined by the presence of $R O R \alpha$ mRNA on adjacent sections. Although $R O R \alpha$ is also expressed in the nearby ventral posterior (VP) nucleus, distinction between VP and dLG was easy with a histological boundary. All the DAPI-positive cells in the dLG nucleus (7-10 sections/thalamus) were counted using ImageJ software. The dLG volume was measured by summing the area of $R O R \alpha$-positive regions. Four thalami were analyzed for each genotype. Statistical analysis was done using two-tailed Student's $t$ test.

Area measurement on tangential sections. The area and length of V1 with respect to the area and length of the entire neocortex of P7 tangential sections were measured in $\mathrm{Olig} 3^{\mathrm{Cre} /+} ; \mathrm{Sh}{ }^{\mathrm{N} / \mathrm{C}}$ mice, Olig $3^{\mathrm{Cre} /+}$; $R 26^{\text {stopSmoM2/+ }}$ mice and their respective littermate controls using ImageJ software. Eight to 13 hemispheres were analyzed for each genotype. Statistical analysis was done using two-tailed Student's $t$ test.

Area measurement on sagittal sections. The gap between S1 and V1 was measured on P7 sagittal sections of $\mathrm{Olig} 3^{\mathrm{Cre} /+} ; \mathrm{Shh}^{\mathrm{N} / \mathrm{C}}$ mice, $\mathrm{Olig} 3^{\mathrm{Cre} /+}$; $R 26^{\text {stopSmoM2/+ }}$ mice and their respective littermate controls using ImageJ software. The low- $C d h 8$ region in layer 4 was used as a landmark of $\mathrm{S} 1$ and V1. Four hemispheres were analyzed for each genotype. For each hemisphere, six sagittal sections at distinct mediolateral levels were com- pared between genotypes. Statistical analysis was done using two-tailed Student's $t$ test.

Area measurement on coronal sections. The medial-lateral position of $\mathrm{V} 1$ was measured on $\mathrm{P} 7$ coronal sections of $\mathrm{Olig} 3^{\mathrm{Cre} /+} ; \mathrm{Shh}^{\mathrm{N} / \mathrm{C}}$ mice, $\mathrm{Olig} 3^{\mathrm{Cre} /}$ $+; R 26^{\text {stopSmoM } 2 /+}$ mice and their respective littermate controls using ImageJ software. Lmo4 expression in layer 4 is absent in V1, forming a sharp medial border of V1. In higher-order visual area as well as retrosplenial cortex, Lmo4 is strongly expressed in upper layers (see Fig. $4 S$ ). We measured the length of Lmo4 expression domain along the line that separates Lmo4-high upper layers from the lower layer (line segments in yellow in $4 \mathrm{~S}$ shows an example). Six hemispheres were analyzed and statistical analysis was done using twotailed Student's $t$ test.

\section{Results}

Conditional manipulations of Shh signaling in the thalamus cause bidirectional changes in the size and cell number of the dorsal lateral geniculate nucleus

The basic-helix-loop-helix (bHLH) transcription factor Olig3 is expressed specifically in thalamic progenitor cells and the zona limitans intrathalamica (ZLI) (Vue et al., 2007). The ZLI is located at the rostral boundary of the thalamus, which in addition to the basal plate, produces the morphogen Shh to regulate diencephalic development (Scholpp and Lumsden, 2010; Vieira et al., 2010; Nakagawa and Shimogori, 2012). Previous studies demonstrated that different levels of Shh signaling is responsible for setting up the positional identity of neural progenitor cells within the thalamus, which in turn is essential for generating the proper number and size of thalamic nuclei (Szabo et al., 2009; Vue et al., 2009; Jeong et al., 2011). Ectopic expression of SmoM2, a constitutively active form of the Shh effector molecule Smoothened (Smo), expanded the molecular identity of rostroventral thalamic progenitors at the expense of caudodorsal identity (Vue et al., 2009). This expansion results in enlargement of rostroventrally located nuclei including the dLG nucleus, which project to the V1 (Vue et al., 2009). Quantitative analysis of these mice showed that the number of DAPI-positive cells in the expanded dLG was increased by twofold (Fig. $1 A, B, I$ ), whereas its volume showed a threefold increase (Fig. $1 J$ ) compared with control littermates. Interestingly, lateral posterior (LP) nucleus, which projects to higher-order visual areas and expresses Calb2 (calretinin), was strikingly shrunken (Fig. $1 E, F$ ).

We next generated mice in which Shh signaling was reduced in the thalamus. Shh is expressed both in the ZLI and the diencephalic basal plate, but only the ZLI express both Shh and Olig3 (Vue et al., 2007). Thus, with the Olig3 ${ }^{\mathrm{Cre}}$ allele, Shh was conditionally knocked out in the ZLI (Bluske et al., 2012). At E12.5, Olig $3^{\mathrm{Cre} /+} ; S h h^{N / C}$ embryos specifically lacked the expression of Shh in the ZLI (Bluske et al., 2012). In these embryos, Olig2 expression in rostral thalamic progenitor cells was reduced (data not shown), reflecting a reduction of rostroventral identity of thalamic progenitor cells (Vue et al., 2007). Dbx1, a marker expressed highly in the caudo-dorsal part of the thalamus (Vue et al., 2007), was rostrally expanded in the same embryos (data not shown). These changes were opposite to those found in mice expressing ectopic SmoM2 (Olig ${ }^{\mathrm{Cre} /+} ; \mathrm{R}_{2} 6^{\text {stopSmoM2/+ }}$ mice) (Vue et al., 2009), and resulted in a reduction of the expression domain of $R O R \alpha$ in the dLG nucleus and reciprocal expansion of the LP nucleus (Fig. 1C,D, G,H). Quantitative analysis of the $R O R \alpha$ expression domain demonstrated that the number of cells within dLG was decreased by $50 \%$, whereas the volume of dLG was decreased by $\sim 65 \%$ in Olig ${ }^{\mathrm{Cre} /+} ; \mathrm{Shh}^{\mathrm{N} / \mathrm{C}}$ mice compared with littermate controls (Fig. $1 C, D, K, L$ ).

By using Netrin-G1 as a TCA marker (Nakashiba et al., 2002), we further found that altering Shh signaling in either direction 

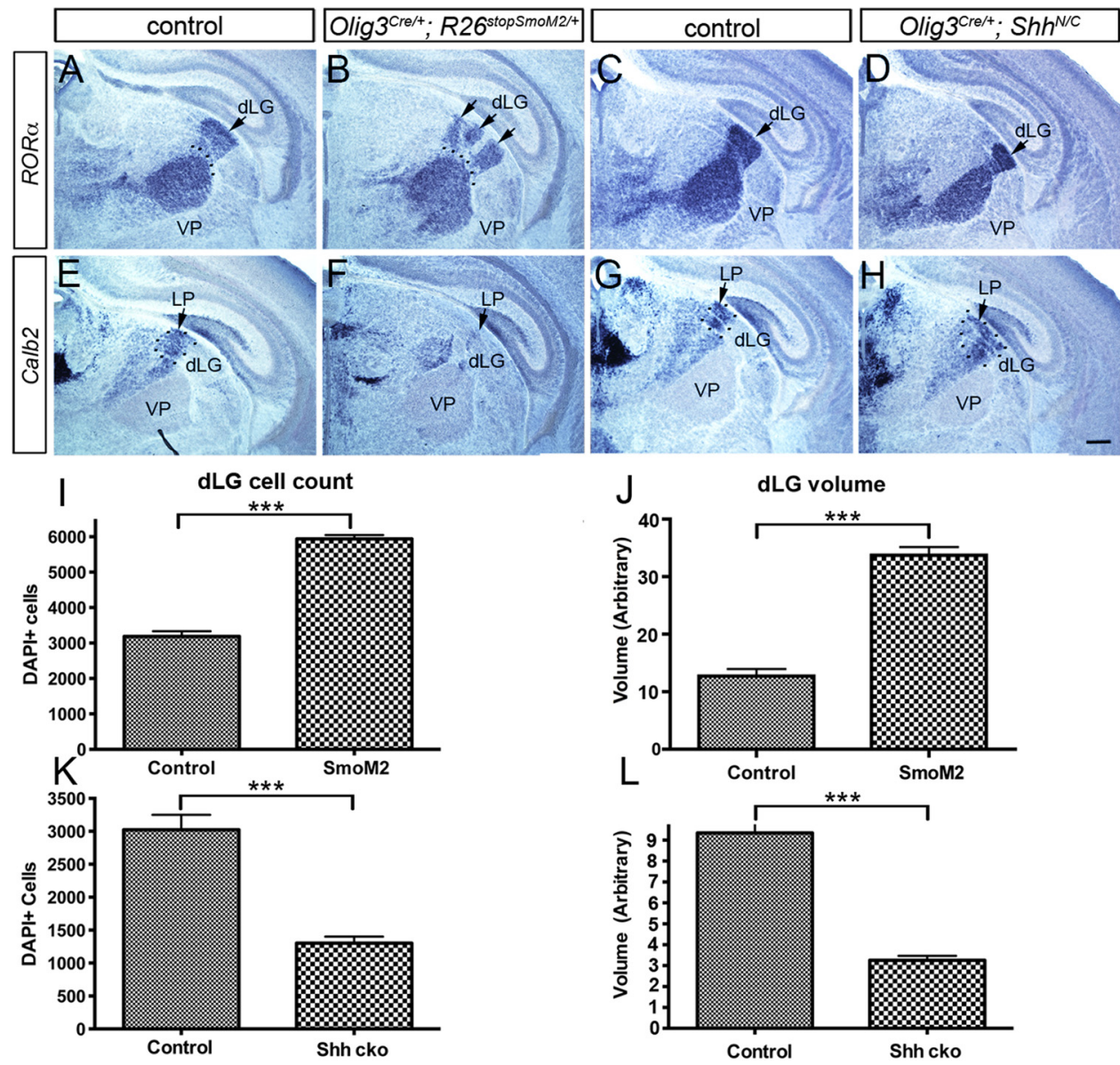

Figure 1. Size and cell number change in the dLG nucleus of the thalamus in mice with elevated or reduced thalamic Shh signaling. $A-D, R O R \alpha$ mRNA expression in the neonatal thalamus of

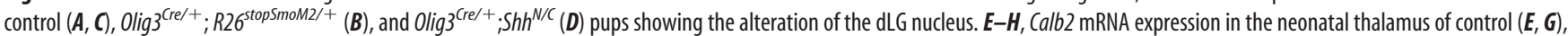
$\mathrm{Olig}^{\mathrm{Cre/}+} ; \mathrm{R}^{2} 6^{\text {stopSmoM2/+}}(\boldsymbol{F})$, and Olig $3^{\mathrm{Cre} /+} ; \mathrm{Shh}^{\mathrm{N} / \mathrm{C}}(\boldsymbol{H})$ pups showing the reciprocal changes of LP nucleus to those of dLG. I, $\boldsymbol{K}$, Comparison of counts of DAPI-positive cells in dLG delineated by $R O R \alpha$ expression. J, L, Comparison of dLG volume. Mean \pm SEM is shown. Statistical significance, ${ }^{* * *} p<0.0005$ in Student's $t$ test; $n=4$ for each genotype. Po, Posterior nucleus. Scale bar, $200 \mu \mathrm{m}$.

within the thalamus does not affect gross patterns of TCA projection at E12.5 and E15.5 (Fig. $2 A-H$ ). Combined with a strong Cre reporter line Ai6 that expresses ZSGreen (Madisen et al., 2010), $\mathrm{Olig}^{\mathrm{Cre}}$ allele showed no sign of recombination within the neocortex until at least P7 (Fig. $2 I-K$ ). We thus expected that the intrinsic patterning of the cortex will be intact in both $\mathrm{Olig}_{3} \mathrm{Cre}^{+}$; $\mathrm{R}^{2} 6^{\text {stopSmoM2/+ }}$ and $\mathrm{Olig} 3^{\mathrm{Cre} /+} ; \mathrm{Shh}^{\mathrm{N} / \mathrm{C}}$ mice. As predicted, regional expression patterns of $R O R \beta, C d h 8$, Id2, EphA7, and Lmo 4 in E17.5 cortical plate were similar to control mice (Fig. $2 P-Y$ ). These results are consistent with earlier reports showing that TCAs are not critically required for neocortical regionalization during embryogenesis (Miyashita-Lin et al., 1999; Nakagawa et al., 1999). Both Olig $3^{\mathrm{Cre} /+} ; \mathrm{Shh}^{\mathrm{N} / \mathrm{C}}$ and $\mathrm{Olig} 3^{\mathrm{Cre} /+} ; \mathrm{R}^{\text {stopSmoM2/+ }}$ mice survived postnatally, and the overall morphology of the P8 forebrain was not different between the genotypes (Fig. $2 L-O$ ).

In summary, we established two postnatally viable mouse models in which the size and number of neurons in the dLG nucleus are bidirectionally altered due to changes in Shh signaling in the thalamic ventricular zone. Changes in the dLG size were accompanied by reciprocal changes of the LP nucleus, which normally project to higher-order visual areas. In these two mutants, timing of TCA projections and cortical patterning were not altered, thereby allowing us to assess the specific roles of geniculocortical afferents in the formation of primary visual cortex.
Expansion or shrinkage of geniculocortical projections alters the size and boundaries of the primary visual area in postnatal cortex

At P7 in control mice, axon terminals from principal sensory nuclei of the thalamus show strong immunoreactivity of serotonin mainly in layer 4 of primary sensory areas (Fig. $3 A, C$ ) (Lebrand et al., 1996). In $\mathrm{Olig}_{3}^{\mathrm{Cre} /+} ; \mathrm{R}_{2} 6^{\text {stopSmoM2/+}}$ mice, the serotonin-positive region in the caudal cortex, which corresponds to the geniculocortical axon terminals, was expanded, whereas it was shrunken in $\mathrm{Olig}_{3} \mathrm{Cre} /+^{+} ; \mathrm{Shh}^{\mathrm{N} / \mathrm{C}}$ brains (Fig. $3 E, G, I, K)$. This indicated that altered cell numbers in the dLG nucleus results in expansion or shrinkage of TCA projections to V1.

We next tested whether the altered geniculocortical projections are accompanied by matching changes in gene expression patterns in V1. In control animals at P7, the distribution of $R O R \beta$, which is known to be strong in layers 4 and 5 of primary sensory areas at this stage as well as in the adult brain (SchaerenWiemers et al., 1997), closely matched with that of serotonin staining on adjacent sections (Fig. $3 A-D$ ). In $\mathrm{Olig} 3^{\mathrm{Cre} /+}$; $R 26^{\text {stopSmoM2/+ }}$ and $\mathrm{Olig} 3^{\mathrm{Cre} /+} ; \mathrm{Shh}^{\mathrm{N} / \mathrm{C}}$ mice, expression of $\mathrm{ROR} \beta$ was altered in the same way as the serotonin signal (Fig. $3 F, H, J, L)$, demonstrating that $\mathrm{V} 1$ is expanded or shrunken in response to the altered size of geniculocortical projections. 


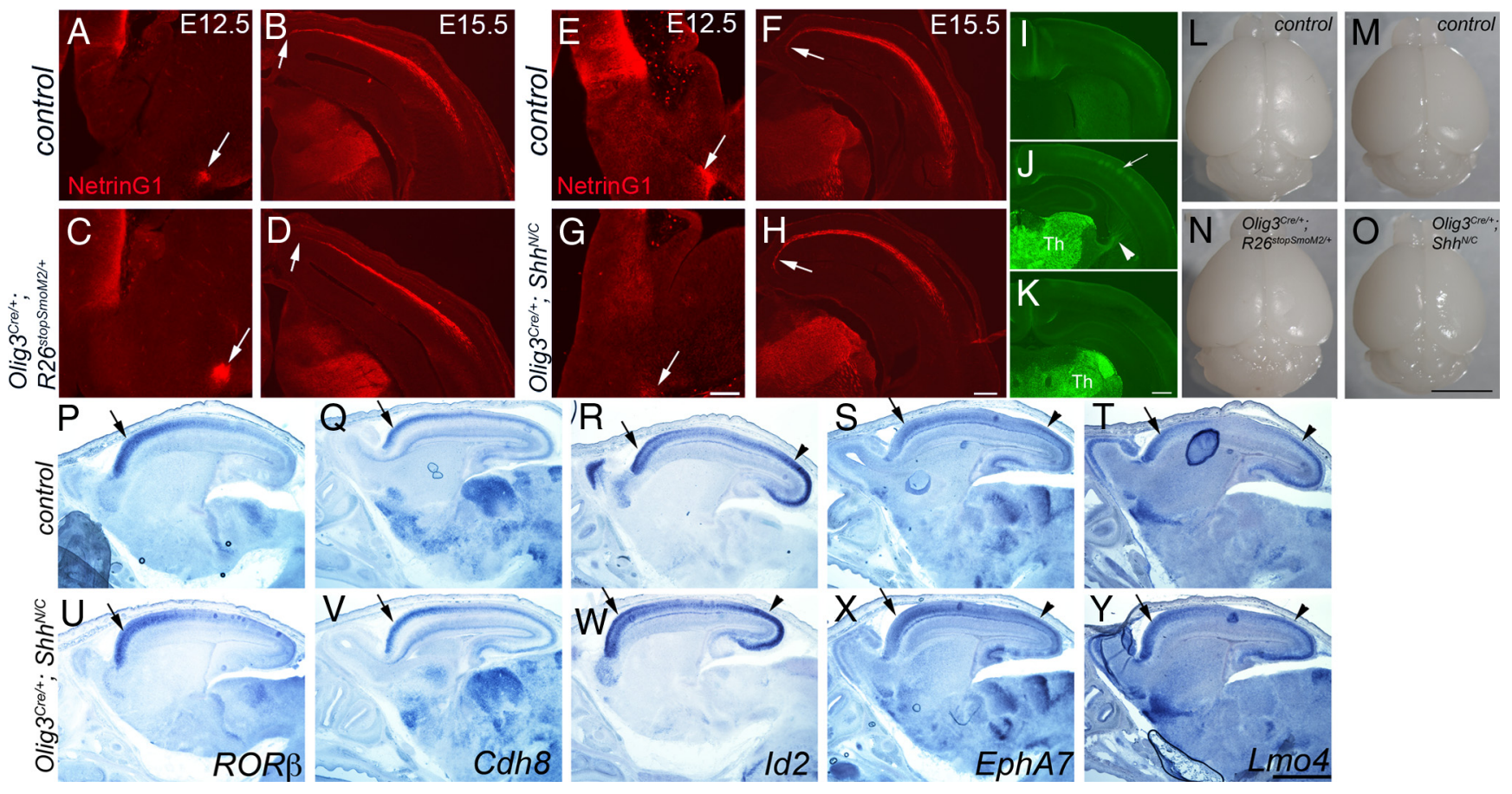

Figure 2. Phenotypes of Olig $3^{\mathrm{Cre} /+} ; \mathrm{R} 26^{\text {stopSmoM2/+ }}$ and Olig ${ }^{\mathrm{Cre}^{+}+} ; \mathrm{Shh}^{\mathrm{N} / \mathrm{C}}$ mice. $\boldsymbol{A - H}$, Normal overall patterns of pathfinding of thalamocortical axons in embryos with altered Shh signaling in the thalamus. Netrin-G1 immunohistochemistry (Nakashiba et al., 2002) on frontal sections of Olig $3^{\text {Cre/+ }} ; R 26^{\text {stopsmom2/+ }}$ embryos and their controls $(\boldsymbol{A}-D)$ or Olig $3^{\text {Cre/ }+} ;$; $h h^{\mathrm{N/C}}$ embryos and their controls $(\boldsymbol{E}-\boldsymbol{H})$. At E12.5, TCAs have just reached the diencephalon-telencephalon border in all genotypes $(\boldsymbol{A}, \boldsymbol{C}, \boldsymbol{E}, \boldsymbol{G})$, although there is consistently stronger signal at the front end of TCAs in

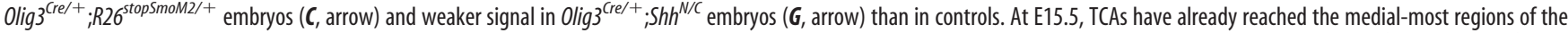

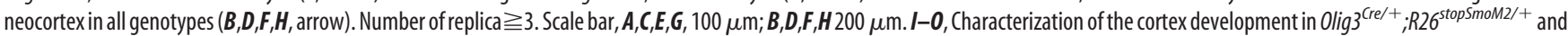

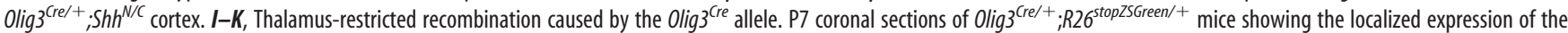
ZSGreen reporter gene in the thalamus. $\boldsymbol{I}$, The most rostral level, and $\boldsymbol{K}$, the most caudal level. Thalamus (Th) shows robust nuclear ZSGreen expression while other forebrain regions show almost no sign of Cre - mediated recombination. Due to the strong fluorescence of ZSGreen, TCAs are also labeled in the internal capsule $(J$, arrowhead) and also in their terminals, particularly in the barrel field of primary somatosensory area $(\boldsymbol{J}$, arrow). However, no nuclear signal is seen in the cortex, showing the lack of recombination. Scale bar, $500 \mu \mathrm{m} . \mathbf{L}-\mathbf{0}, 0$ verall morphology of the cerebral cortex is

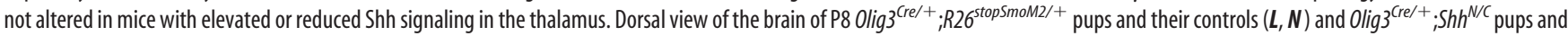
their controls $(\boldsymbol{M}, \mathbf{0})$. Cerebral cortex seems to be unaltered in overall morphology and size. Scale bars, $5 \mathrm{~mm}$. $\boldsymbol{P}-\boldsymbol{Y}$, Regional gene expression patterns in the cortical plate of E17.5 embryos are not significantly affected with altered Shh signaling in the thalamus. In situ hybridization on sagittal sections of 0 lig ${ }^{C \text { re/ }}{ }^{+} ; S h h^{N / C}$ embryos and their controls. Rostral is to the left. $R O R \beta(P, \boldsymbol{U})$ and $(d h 8$ $(\boldsymbol{Q}, \boldsymbol{V})$ are expressed in high-rostral to low-caudal gradients in the cortical plate (arrow indicates the regions with high level of expression). Id2 (R, W), EphA7 (S,X), and $L m 04(\boldsymbol{T}, \boldsymbol{Y})$ all show high expression in the rostral (arrow) and caudal (arrowhead) parts of the cortex and their expression level drops in the middle part. These general patterns of differential expression are unaffected in $\mathrm{Olig}^{3^{\text {ree/ }} ; \text {; Shh }}{ }^{\mathrm{N} / \mathrm{C}}$ embryos. Number of replica $\geqq 3$. Scale bars, $1 \mathrm{~mm}$.

In addition to $R O R \beta$, other markers for $\mathrm{V} 1$ borders including Lmo4, Cdh8, and Id2 were analyzed on adjacent sections (Fig. 4). In this analysis, we used serially adjacent sections for the four molecular markers (Fig. $4 A-D, E-H, I-L$, and $M-P$, from adjacent sections). Lmo4 was expressed in layers 2, 3, and 4 of the medial cortex (Fig. 4B,J). The lateral border of this $L m o 4$ expression domain (Fig. $4 B, J$, medial arrow) matched with the medial border of ROR $\beta$ (Fig. 4A, I, medial arrow) on adjacent sections, delineating the medial border of V1. We further confirmed the matching gene expression borders by double immunostaining of Lmo4 and ROR $\beta$ on the same section (Fig. $4 Q, R$ ). Cdh 8 expression was detected in layers $2-5$ of visual areas, but layer 4 in V1 showed specifically low expression (Fig. $4 C, K$, between black arrows). Expression of Id2 in layer 6 also marked V1. In $\mathrm{Olig}_{3} \mathrm{Crel}^{+}$; $S h h^{N / C}$ mice, the medial border of $R O R \beta$ expression in both layers 4 and 5 was shifted laterally compared with controls at all rostrocaudal levels examined (Fig. $4 A, E$ ). The same shift was found for Lmo4 (Fig. $4 F$ ), Cdh8 (Fig. 4G), and Id2 (Fig. 4H). In contrast, in $\mathrm{Olig} 3{ }^{\mathrm{Cre} /+} ; \mathrm{R}_{2} 6^{\text {topSmoM } 2 /+}$ mice, a medial shift of the medial border of V1 was found for all of the above markers (Fig. $4 I-P)$. The distance from the medial border of $\mathrm{V} 1$ to the midline was quantitatively evaluated by measuring the length of the medial expression domain of Lmo4, which starts at the medial bor- der of V1 and ends at the medial border of retrosplenial cortex, abutting the subiculum (Fig. 4S). We found that this distance was decreased in $\mathrm{Olig}^{\mathrm{Crel} /+} ; \mathrm{R}^{2} 6^{\text {stopSmoM2/+ }}$ mice and increased in $\mathrm{Olig} 3^{\mathrm{Cre} /+} ; \mathrm{Shh}^{\mathrm{N} / \mathrm{C}}$ mice in comparison with their respective control littermates (Fig. 4T,U). In contrast, the lateral border of V1, which is indicated by the lateral border of low $C d h 8$ expression in layer 4 , did not seem to be significantly shifted (Fig. 4C,G, $K, O$ ). These results show that along the mediolateral axis, V1 is contracted in $\mathrm{Olig} 3^{\mathrm{Cre} /+}$; $\mathrm{Sh}^{\mathrm{N} / \mathrm{C}}$ mice and expanded in $\mathrm{Olig}_{3}{ }^{\mathrm{Cre} /+}$; $R 26^{\text {stopSmoM2/+ }}$ mice. Similar changes in gene expression for these markers were already evident at P3 at least in $\mathrm{Olig}_{3} \mathrm{Cre}^{+}$; $R 26^{\text {stopSmoM2/+ }}$ mice (data not shown). These data suggest that the size and shape of $\mathrm{V} 1$ are significantly altered in $\mathrm{Olig}_{3} \mathrm{Cre}^{+}$; R2 $6^{\text {stopSmoM2/+ }}$ and Olig $3^{\mathrm{Cre} /+} ; \mathrm{Shh}^{\mathrm{N} / \mathrm{C}}$ mice, and the influence of geniculocortical axons on $\mathrm{V} 1$ in these mice was not limited just to layer 4, but was also detected in layers 2, 3, 5, and 6 .

Finally, to determine how the overall size and shape of $\mathrm{V} 1$ are altered in correspondence to the changes in TCA terminations, the dimensions of V1 were measured on tangential sections by comparing serotonin staining and $R O R \beta$ expression on adjacent sections between the different genotypes. As on coronal sections, we found that serotonin staining and $R O R \beta$ expression in V1 precisely match in $\mathrm{Olig} 3^{\mathrm{Crel+}} ; \mathrm{R}^{6^{\text {stopSmoM2/+}}}{ }^{\mathrm{O}} \mathrm{Olig}^{\mathrm{Cre} /+} ; \mathrm{Shh}^{\mathrm{N} / \mathrm{C}}$, 

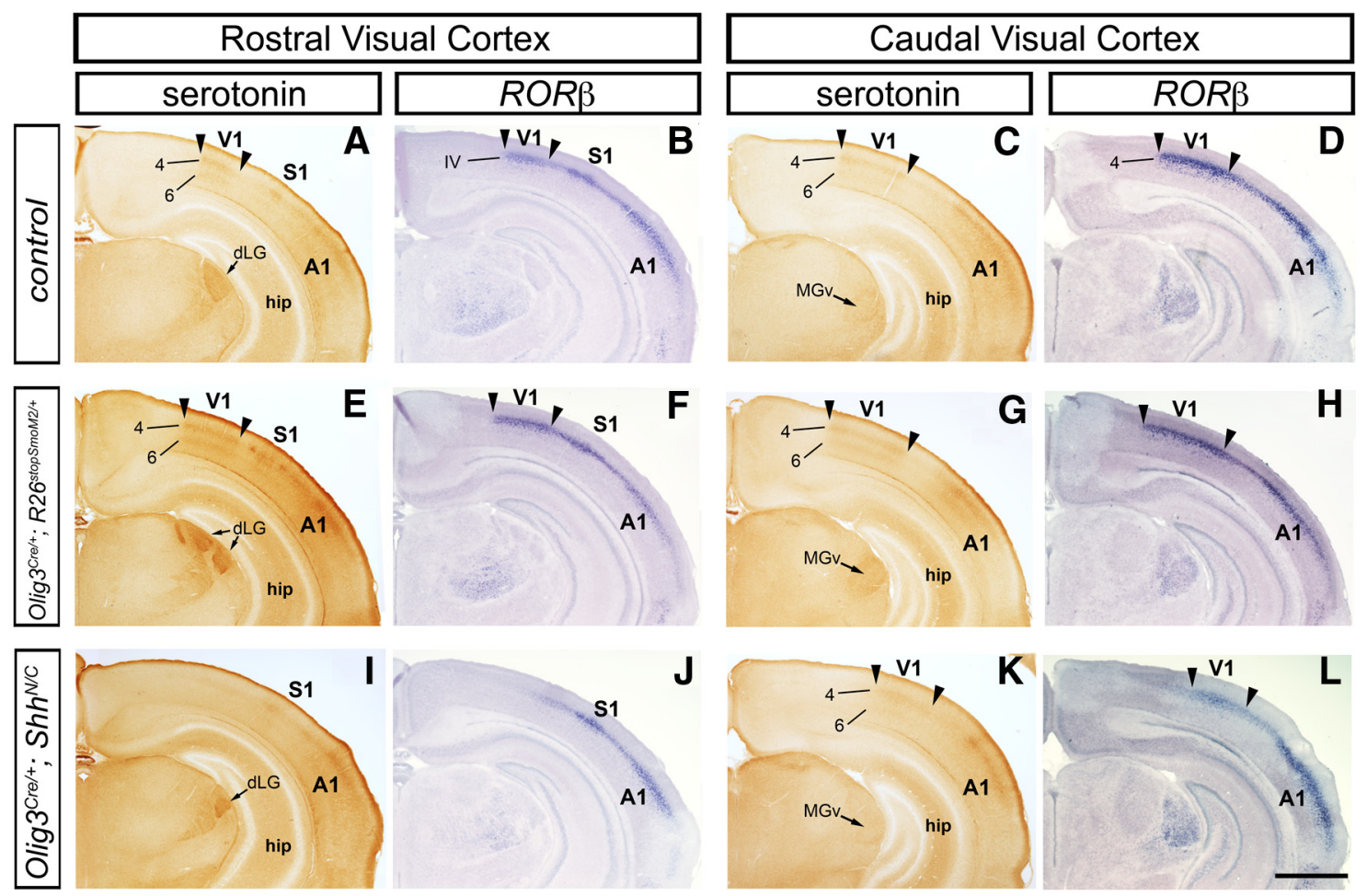

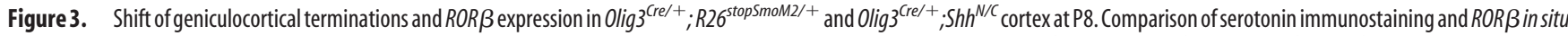
hybridization on adjacent coronal sections through the rostral visual cortex and more caudal visual cortex between control, Olig $3^{\mathrm{Cre} /+} ; R 26^{\text {stopsmoM2/+}}$, or $\mathrm{Olig} 3^{\mathrm{Cre} /+} ; \mathrm{Sh} h^{\mathrm{N/C}}$ mice at P7. A-D, Control sections showing the width, or medial-lateral boundaries, of V1 as labeled by serotonin staining or ROR $\beta$ expression at a rostral level $(\boldsymbol{A}, \boldsymbol{B}$, arrowheads) or more caudal level ( $\boldsymbol{C}, \boldsymbol{D}$, arrowheads). The dLG nucleus is also labeled by serotonin staining (A, arrow). $\boldsymbol{E}-\boldsymbol{H}$, Coronal sections of an $\mathrm{Olig} 3^{\text {(re/ } /+} ; R 26^{\text {stopsmoM2/+ }}$ brain showing that not only is serotonin staining in layers 4 and 6 of $\mathrm{V} 1$ more intense than control, but the width of $\mathrm{V} 1$ as labeled by both serotonin and ROR $\beta$ is expanded ( $\boldsymbol{E}-\boldsymbol{H}$, arrowheads). The size of dLG is also expanded ( $\boldsymbol{E}$, arrows). $\boldsymbol{I}-\boldsymbol{L}$, Coronal sections of an Olig $3^{\text {(re/ }+} ; S h h^{N / C}$ brain showing that serotonin staining and ROR $\beta$ in situ hybridization did not detect any expression in the rostral visual cortex $(I, J)$ but only at the caudal visual cortex, indicating a caudal shift of the rostral boundary of V1 in these mice. Note that the level of serotonin staining is also decreased, the width of V1 is reduced, and boundaries of V1 are shifted more laterally compared with controls ( $\boldsymbol{K}, \boldsymbol{L}$, arrowheads). The dLG is also significantly smaller in size ( $\boldsymbol{I}$, arrow). Number of replica, 7 for $\boldsymbol{E}-\boldsymbol{H}, 4$ for $\boldsymbol{I}-\boldsymbol{L}$. Scale bar, $1 \mathrm{~mm}$.

and their respective control mice, and the relative size of $\mathrm{V} 1$ was expanded in $\mathrm{Olig} 3^{\mathrm{Cre} /+} ; \mathrm{R}_{2} 6^{\text {stopSmoM2/+}}$ and shrunken in $\mathrm{Olig} 3^{\mathrm{Cre} /+}$; $S h h^{N / C}$ mice, both in area and rostrocaudal length ratios against the total cortex (Fig. 5A-H). The gap between V1 and $\mathrm{S} 1$ contains higher-order sensory areas. This gap was narrowed in $\mathrm{Olig}^{\mathrm{Cre} /+}$; $\mathrm{R}_{2}{ }^{\text {stopSmoM2/+ }}$ and widened in $\mathrm{Olig} 3^{\mathrm{Cre} /+} ; \mathrm{Shh}^{\mathrm{N} / \mathrm{C}}$ mice (Fig. $5 A-F$, between bars). Quantitative analysis of $C d h 8$ expression in layer 4 on sagittal sections at P8 confirmed the change in the gap between V1 and S1 (Fig. 5I-N). The altered gap width between $\mathrm{V} 1$ and $\mathrm{S} 1$ indicates that the shift of V1 boundaries is accounted for by a switch of areal fate from primary to higher-order sensory areas or vice versa. The reciprocal changes in the size of the dLG and LP nuclei in both Olig ${ }^{\mathrm{Cre} /+} ; \mathrm{R}_{2} 6^{\text {stopSmoM2/+ }}$ and $\mathrm{Olig} 3^{\mathrm{Cre} /+}$; $S h h^{N / C}$ mice (Fig. 1) imply that thalamic afferents from principal sensory nuclei and other nuclei play distinct roles in conferring areal identity to their respective target region in the neocortex.

Thalamus-specific Gbx2 mutant mice survive postnatally and show severe deficiency of thalamocortical axon projections to the neocortex

In both Olig $3^{\mathrm{Cre} /+} ; \mathrm{R}_{2} 6^{\text {stopSmoM2/+}}$ and $\mathrm{Olig}^{\mathrm{Cre} /+} ; \mathrm{Shh}^{\mathrm{N} / \mathrm{C}}$ mice, the relative sizes of $\mathrm{dLG}$ and LP nuclei were changed as a result of altered Shh signaling in thalamic progenitor cells, whereas the overall TCA trajectory to the cortex was not significantly affected. In this light, determining the default state of cortical development without any influence by TCAs would provide insights into the nature of the specific roles of primary sensory and other types of TCA afferents. We therefore generated thalamus-specific Gbx2 mutant mice, in which TCA projection to the neocortex was found to be nearly absent from the outset of its development.

Gbx2 encodes a homeodomain-containing transcription factor expressed in nearly all cortex-projecting postmitotic neurons in the thalamus at E12.5 (Bulfone et al., 1993; Chen et al., 2009), although its expression later becomes restricted to several nuclei (Nakagawa and O'Leary, 2001; Jones and Rubenstein, 2004; Li et al., 2012). Gbx2 is also expressed at the midbrain-hindbrain boundary, in the spinal cord and in cholinergic neurons of the ventral telencephalon. Germ-line deletion of $G b \times 2$ in mice resulted in the lack of TCA projections to the cortex (Miyashita-Lin et al., 1999; Hevner et al., 2002). Although these mutant mice die at birth, differential gene expression in the neonatal cortical plate showed normal patterns, which indicated the sufficiency of intrinsic cortical patterning in early phases of area formation (Miyashita-Lin et al., 1999).

To avoid the neonatal lethality so that we could determine the roles of TCAs in cortical development during both embryonic and postnatal stages, we generated conditional $G b \times 2$ mutant mice using the Olig $3^{\mathrm{Cre}}$ allele $\left(\mathrm{Olig} 3^{\mathrm{Cre} /{ }^{+}} ; \mathrm{Gb} \times 2^{\mathrm{C} / \mathrm{C}}\right.$ mice or $\mathrm{Gb} \times 2$ cko mice). We first found that $G b \times 2$ cko mice survive postnatally, up to 5-6 weeks after birth. At E12.5 and E14.5, the mutant mice showed near-complete deletion of the floxed exon2 of the Gbx2 gene in the thalamus, whereas its expression in the ventral telencephalon was preserved (Fig. $6 A, B, D, E$ and data not shown). Expression of $R O R \alpha$, which mainly labels principal sensory nu- 


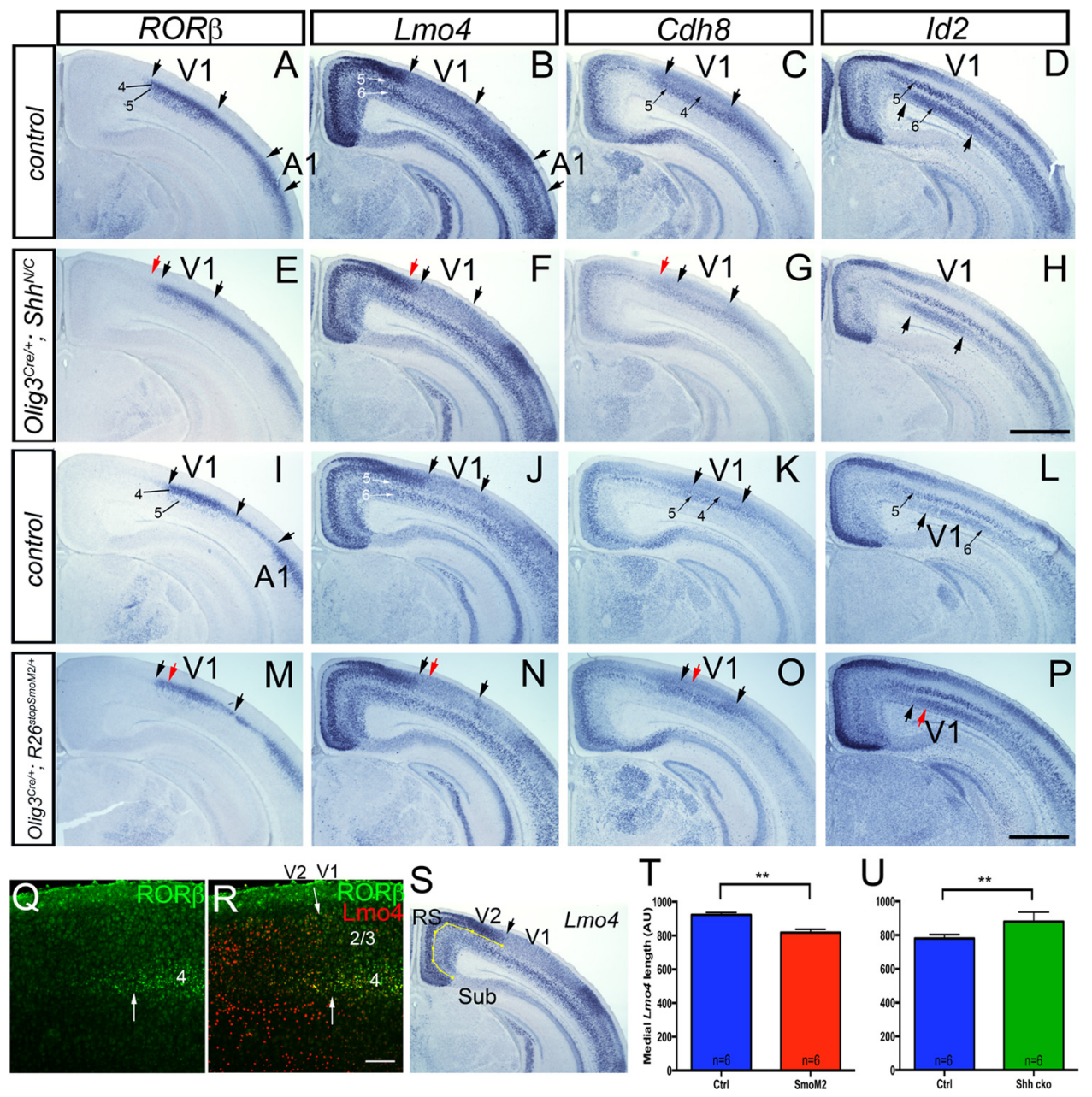

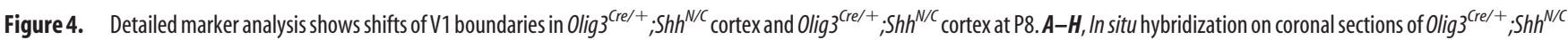

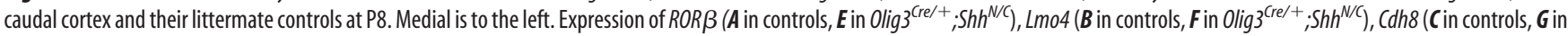
Olig $3^{\text {(re/ }+} ; S h h^{N / C}$ ), and Id2 ( $\boldsymbol{D}$ in controls, $\boldsymbol{H}$ in Olig $3^{(\text {re/ }+} ; S h h^{N / C}$ ) is shown. $\boldsymbol{A}-\boldsymbol{D}$ and $\boldsymbol{E}-\boldsymbol{H}$ are serially adjacent sets of sections taken from the same brain. Medial black arrow in $\boldsymbol{A}-\boldsymbol{C}$ coincides well with each other and represents the medial border of V1. Lateral black arrow in $A-C$ represent the lateral border of $\mathrm{V} 1$ and its position is based on the lateral border of weak $C d h 8$ expression in layer 4 ( $($ ). Arrows in $\boldsymbol{D}$ are based on the positions of V1 borders obtained from the adjacent section shown in $\boldsymbol{C}$. Black arrows in $\boldsymbol{E}-\boldsymbol{H}$ were obtained in the same way as for $\boldsymbol{A}-\boldsymbol{D}$. Red arrows in $\boldsymbol{E}-\boldsymbol{H}$ correspond to the medial border of $\mathrm{V} 1$ in corresponding control sections shown immediately above and indicate the shift of boundaries in 0 lig ${ }^{\mathrm{Cre} /+}{ }_{;}$; Shh ${ }^{\mathrm{N} / \mathrm{C}}$ mice. This is confirmed by quantification shown in $\boldsymbol{U}$. Number of replica, 6 . Scale bar, $1 \mathrm{~mm}$. I-P, In situ hybridization on coronal sections of Olig $3^{\text {Cre/+ }} ; R 26^{\text {stopsmoM2/+ }}$ caudal cortex and their littermate controls at P8. Medial is to the left.

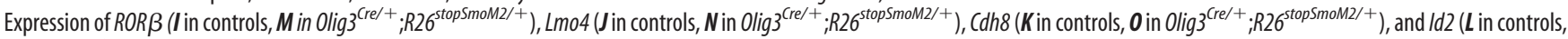
$\boldsymbol{P}$ in Olig $\left.3^{(\mathrm{rre} /+} ; R 26^{\text {stopSmoM2/+}}\right)$ is shown. $\boldsymbol{I}-\boldsymbol{L}$ and $\boldsymbol{M}-\boldsymbol{P}$ are serially adjacent sets of sections taken from the same brain. Black arrows show V1 boundaries obtained by the same methods used in $\boldsymbol{A}-\boldsymbol{H}$, whereas red arrows indicate the shift of boundaries in Olig $3^{\mathrm{Cre} /+} ; R 22^{\text {stopsmoM2/+ }}$ mice. This is confirmed by quantification shown in $\boldsymbol{T}$. Number of replica, 4. Scale bar, $1 \mathrm{~mm}$. $\mathbf{Q}, \boldsymbol{R}$, Double immunostaining of ROR $\beta$ (green) and Lmo4 (red) at the V1/V2 border of P8 cortex. Medial is to the left. Q shows the single color for ROR $\beta$ staining and R shows double staining on the same section. Note that the medial border of ROR $\beta$ expression and lateral border of $\mathrm{Lm04}$ expression match (arrow). Scale bar, $100 \mu \mathrm{m}$. S-U, Shifts of medial boundary of 1 in Olig $3^{\text {(ree/ }}$; Shh ${ }^{N / C}$ and Olig $3^{\text {(re/ }+} ; R 26^{\text {stopSmoM2/+ }}$ mice on coronal sections at P8.S. Distance between the midline and medial border of V1 as determined by the expression of $L m 04$. Midline was defined as the medial end of the retrosplenial area (RS) indicated by the end of high Lmo4 expression domain in upper layers. This domain includes higher-order visual area (V2) and retrosplenial area (RS). Length of the segmented line (yellow) was measured. Sub, Subiculum. $T$, Comparison of the length of $L$ mo4 expression domain between Olig $3^{\text {(re/ } /+} ; R 26^{\text {stopSmoM2/+ }}$ and control mice (mean $\left.\pm S E M\right)$. The medial border of $\mathrm{V} 1$ in SmoM2 cortex shows a medial shift. $\boldsymbol{U}$, Comparison between Olig $3^{\mathrm{Cre} /+}$; Shh ${ }^{\mathrm{N/C}}$ and control mice (mean $\pm \mathrm{SEM}$ ). The medial border of V1 in the mutant cortex shows a lateral shift. Statistical significance, ${ }^{* *} p<0.005$ in Student's $t$ test; $n=6$ for each genotype.

clei of the thalamus (Nakagawa and O'Leary, 2003), is severely reduced in $G b x 2$ cko mice (Fig. $6 C, F$ ).

Due to the early expression of $G b \times 2$ at midbrain-hindbrain boundary and the contribution of brainstem Raphe neurons in providing serotonergic innervation to the cortex, we tested the effects of using the $\mathrm{Olig}_{3}{ }^{\mathrm{Cre}}$ allele on these neuronal populations. Although the Olig $3^{C r e}$ allele mediates recombination in dorsal hindbrain region that is fated to produce precerebellar nuclei including the inferior olive (Liu et al., 2008; Storm et al., 2009), we did not detect an overlap between recombined cells and serotonergic neurons at E12.5 (Fig. 6G). Furthermore, serotonergic neurons in dorsal and medial Raphe nuclei seemed intact in $G b \times 2$ cko mice at E14.5 (Fig. $6 \mathrm{H}, \mathrm{I}$ ), and serotonergic projections from the Raphe neurons appeared normal through the septum into the cortex at E16.5 (Fig. 6J,K). Therefore, in Gbx2 cko mice, the cortex is specifically deprived of afferent projections from the thalamus but not from the brainstem Raphe nuclei.

Detailed analysis of TCAs of $G b \times 2$ cko mice showed profound deficiency from the initial phase of their projections toward the cortex. Already at E12.5, TCAs failed to reach the diencephalontelencephalon border (Fig. 7A-D). By E14.5, when TCAs have normally reached the neocortex, only a small axon bundle was found in the ventral telencephalon of $G b \times 2$ cko mice (Fig. 7E-H). At E16.5, a faint labeling of Netrin-G1-expressing TCAs was 

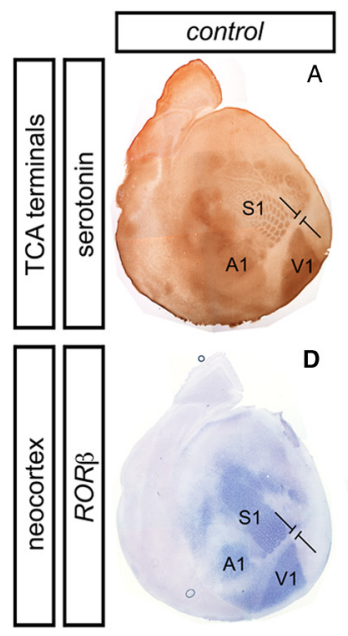

D

G

H

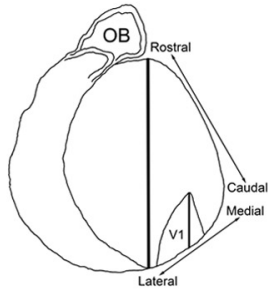

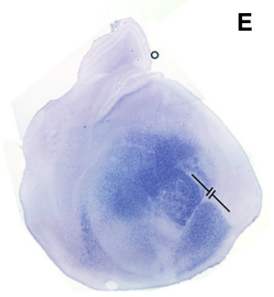

E
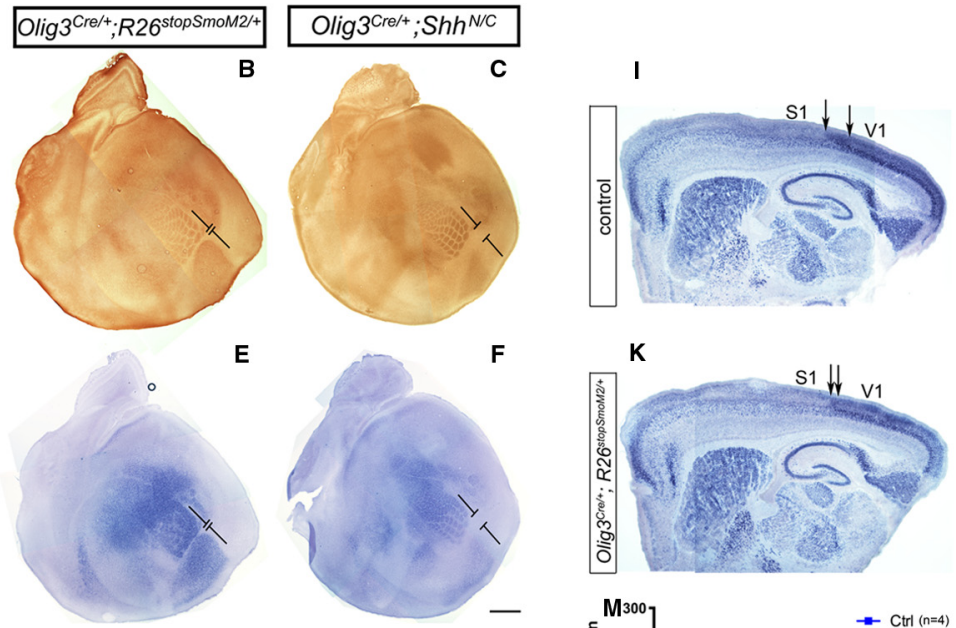

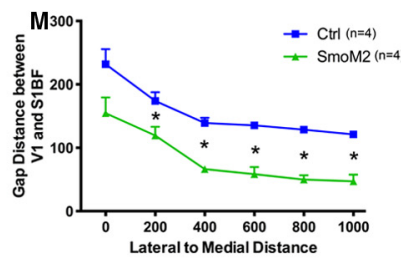

$\mathbf{J}$
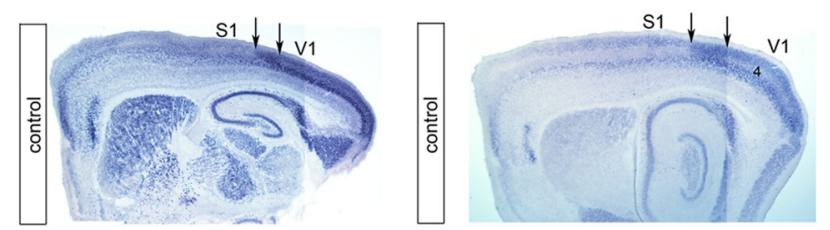

L
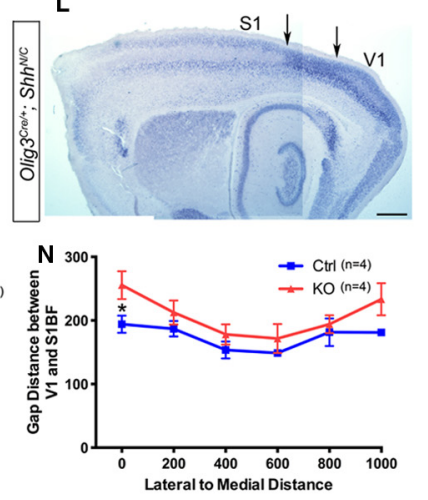

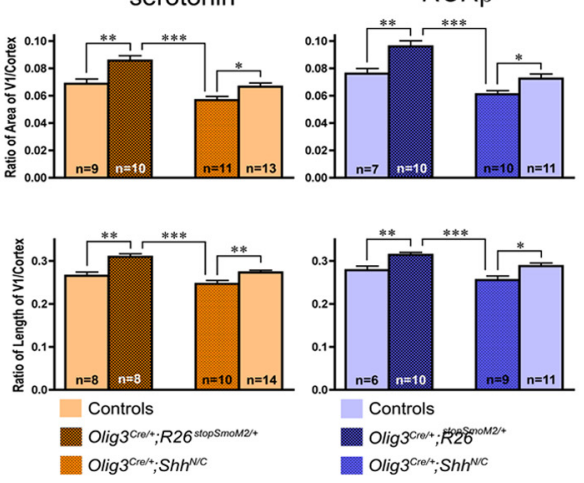

Figure 5. Measurements of V1 boundaries in 0 lig $3^{\text {Cre/ }+} ; R 26^{\text {stopSmoM2/+ }}$ and 0 lig $3^{\text {Cre/ }+} ; \mathrm{Shh}^{\mathrm{N} / \mathrm{C}}$ cortex at P7/P8.A-F, Comparison of the size and shape of V1 using serotonin immunostaining and $R O R \beta$ in situ hybridization on adjacent tangential sections of the flattened neocortex between control, Olig $3^{\text {Cre/ }+} ;$; R2 $6^{\text {stopsmoM2/+ }}$, and Olig $3^{\text {Cre/ }+}$; Shh ${ }^{N / C}$ mice at P7. Serotonin staining labels TCA terminals from sensory thalamic nuclei including the dLG nucleus, whereas $R O R \beta$ expression labels cells in V1. Axes of the flattened cortex are shown in $G$. $A, D$, Adjacent control brain sections showing that both serotonin staining and $R O R \beta$ expression label the same triangle-shaped V1, as well as $S 1$ and A1. Note that there is a clearly defined gap between V1 and $S 1$ (between bars, $A$, $D$ ). $B, E$, Adjacent $O$ lig $3^{\text {(re/ }+} ; R 26^{\text {stopSmoM2/+ }}$ brain sections showing that the shape of $\mathrm{V} 1$, as labeled by both serotonin staining or $R O R \beta$ expression, is more rounded, especially at the rostral tip compared with controls. The size of V1 is enlarged, which is reflected in part by a significant decrease in the gap between V1 and S1. C, $\boldsymbol{F}$, Adjacent 0 lig ${ }^{3^{(r e /+}+} ; S h h^{N / C}$ brain sections showing that the triangular shape of $\mathrm{V} 1$ is preserved but its size is significantly reduced and is also shifted caudally. Note that the gap between V1 and S1 is now approximately twice the size of control. Scale bar, 1 $\mathrm{mm} . \boldsymbol{G}, \boldsymbol{H}$, Quantification of changes in the area and length of $\mathrm{V} 1$, as revealed by serotonin staining (left column, $\boldsymbol{H}$ ) or ROR $\beta$ expression (right column, $\boldsymbol{H}$ ), in $\mathrm{Olig} 3^{\text {(re/ } /+} ; R 26^{\text {stopsmoM2/+ }}$ and Olig $3^{\text {(re/ }+} ;$; Shh ${ }^{N / C}$ brains compared with their respective controls (mean \pm SEM). G, Schematic illustration showing the area ratio (area of V1 divided by the area of the entire cortex) and length ratio

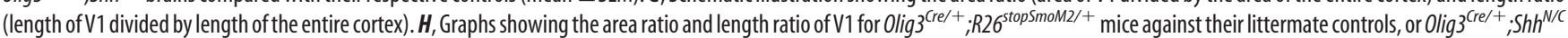
mice against their controls. Number of hemispheres used for analyses are indicated within bar graph of each genotype. Statistical significance, ${ }^{*} p<0.05$; ${ }^{* *} p<0.005$; ${ }^{* * *} p<0.0001 .0 \mathrm{~B}, 0$ lfactory

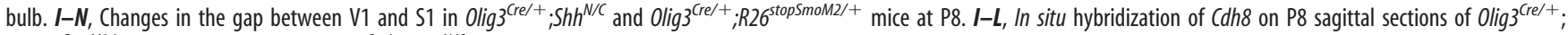
$R 26^{\text {stopsmoM2/+ }}$ and controls $(\boldsymbol{I}, \boldsymbol{K})$ and $\mathrm{Olig} 3^{\text {(re/ } /+} ; S h h^{N / C}$ and controls $(\boldsymbol{J}, \boldsymbol{L})$. Rostral is to the left. Rostral border of $\mathrm{V} 1$ and caudal border of $\mathrm{S} 1$ are defined by the gap region in which strong $C$ dh 8 expression is seen in layer 4 , and are shown by arrows. $\boldsymbol{M}, \boldsymbol{N}$, The gap between $\mathrm{V} 1$ and $\mathrm{S} 1$ was measured in sagittal sections at six different medial-lateral levels from 5 to 6 hemispheres. The gap

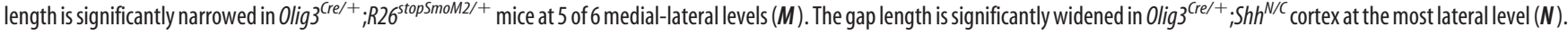
Mean \pm SEM is shown in $\boldsymbol{O}$ and $\boldsymbol{P}$. Statistical significance, ${ }^{*} p<0.05$ in Student's $t$ test; $n=4$ for each genotype. Scale bars, $500 \mu \mathrm{m}$.

barely detected in the neocortex (Fig. $7 I, J$ ). These results demonstrate that $G b \times 2$ expression in the thalamus is required for TCA projection to the cortex. Placement of axon tracers in putative $\mathrm{S} 1$ and V1 at P8 showed a severely decreased connections between the neocortex and the thalamus (Fig. $7 K, L$ ). Thus, the defects in TCA projections persist into postnatal stages. At P21, the thalamus was further disorganized. In Nissl staining, we could not detect dLG or VP, and there was a severe deficiency of internal capsule, indicating that there is no recovery of TCA defects in Gbx2 cko mice (Fig. $7 U, V$ ).

In summary, $G b \times 2$ cko mice provide us with a robust model system to test the requirement of thalamic afferents in the formation of neocortical development both during embryonic and postnatal stages.

\section{Distinct areal and laminar gene expression patterns are disrupted in postnatal neocortex of conditional $G b x 2$ mutant mice}

At E17.5, overall regional gene expression patterns in the cortical plate appeared normal in $G b x 2$ cko mice (Fig. $7 M-T$ ), which is similar to a previous study of germline Gbx2 mutants (Miyashita-Lin et al., 1999). However, by the end of the first postnatal week we found specific defects in areal and laminar gene expression patterns (Fig. 8).

As in V1 (Fig. 4), ROR $\beta$ expression in the control cortex was strong in layer 4 in S1 and A1, and faint in the motor area as well as areas adjacent to primary sensory areas (Fig. $8 A-E$ ). In $G b x 2$ cko cortex, such distinction was no longer evident; ROR $\beta$ expression was decreased in primary sensory areas and increased in the motor cortex (Fig. $8 F-J$ ). In particular, the robust thickening of 


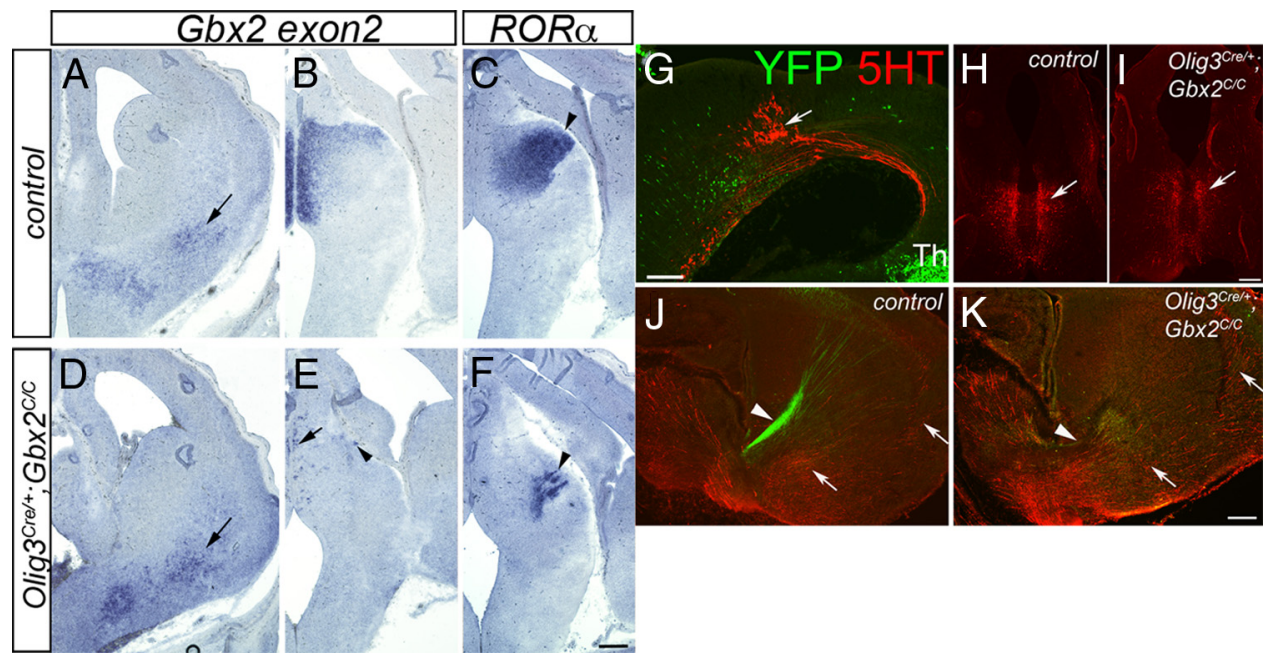

Figure 6. The thalamus, but not the ventral telencephalon and the brainstem Raphe nuclei, is disorganized in Gbx2 cko mice. $A-F$, In situ hybridization on frontal sections of E14.5 Olig $3^{\text {(re/ }++}$; $G b \times 2^{C / C}$ embryos and their controls. Medial is to the left. Exon 2 of the $G b x 2$ genes is specifically deleted in the thalamus (compare $\boldsymbol{B}, \boldsymbol{E}$ ) but not in the ventral telencephalon $(\boldsymbol{A}, \boldsymbol{D})$. ROR $\alpha$ expression in the thalamus is dramatically reduced in the cko embryos (compare $\boldsymbol{C}, \boldsymbol{F}$ ). Scale bar, $200 \mu \mathrm{m}$. $\mathbf{G}-\boldsymbol{K}$, Olig $3^{\text {Cree }}{ }^{-}$mediated recombination does not affect serotonergic neurons in the brainstem of Gbx2 cko mice. $\mathbf{G}$, Sagittal section of E12.5 Olig $3^{\text {(re/ }+} ; R 26^{\text {stopYFP/+ }}$ embryo showing the cells that have undergone recombination with the Olig $3^{\text {(re }}$ allele. Recombined cells that express YFP are negative for serotonin (5HT). The arrow indicates serotonergic neurons. $\mathbf{H}, \mathbf{I}$, Serotonin immunostaining on frontal sections of $G b \times 2$ cko and its littermate control embryos at E12.5. Serotonin-expressing Raphe neurons in the brainstem appear to be intactin $G b \times 2$ cko mice.J, $\boldsymbol{K}$, Immunostaining of serotonin (red) and Netrin-G1 (green) on sagittal sections of Gbx2 cko and its littermate control embryos at E16.5. Rostral is to the right. Projections of serotonergic fibers from Raphe neurons into the cortex (arrows) appear to be comparable between Gbx2 cko and controls, whereas Netrin-G1-labeled TCAs (arrowhead) are markedly diminished in Gbx2 cko embryos. Note that at this stage serotonin and Netrin-G1 label largely nonoverlapping axonal populations in control brains. Scale bars: $\boldsymbol{A}, 100 \mu \mathrm{m} ; \boldsymbol{B}-\boldsymbol{E}, 200 \mu \mathrm{m}$.
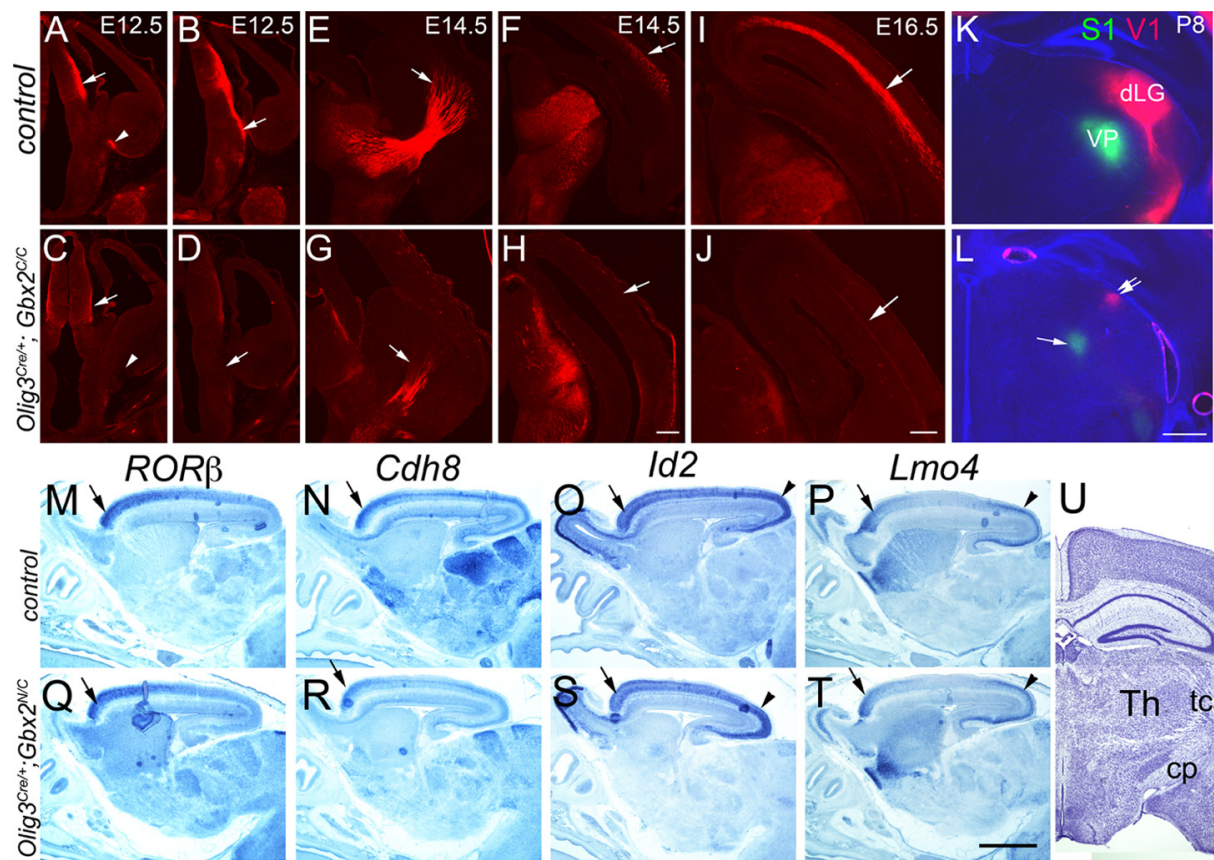

Cdh8
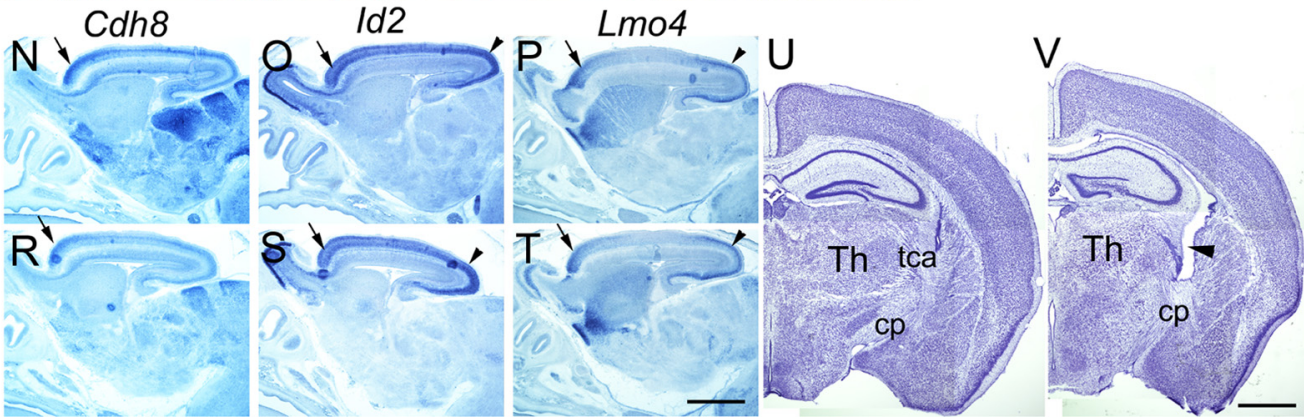

Figure 7. Defects in TCA projections to the cortex and normal embryonic gene expression in the cortex in Gbx2 cko mice. $A-J$, Immunohistochemistry for Netrin-G1, which marks TCAs. Gbx2 cko and control embryos are compared at E12.5 ( $\boldsymbol{A}, \boldsymbol{B}$ for controls; $\boldsymbol{C}, \boldsymbol{D}$ for $\mathrm{Cko}), \mathbf{E} 14.5$ ( $\boldsymbol{E}, \boldsymbol{F}$ for controls, $\boldsymbol{G}, \boldsymbol{H}$ for cko) and E16.5 (I for control, $\boldsymbol{J}$ for cko). Medial is to the left. $\boldsymbol{K}-\boldsymbol{L}$, Retrograde labeling of thalamic neurons by the axon tracers NeuroVue. Pieces of two tracers were placed in $\mathrm{V} 1$ and $\mathrm{S} 1$ of $\mathrm{P} 8$ cortex ( $\boldsymbol{K}$ for control, $\boldsymbol{L}$ for $(\mathrm{k}$ ). Arrow and double arrow in $\boldsymbol{L}$ indicate the severely reduced labeling

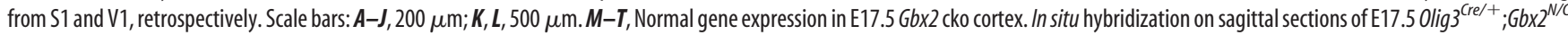
embryos and their controls. Rostral is to the left. $R O R \beta(M, Q)$ and $C d h 8(\boldsymbol{N}, \boldsymbol{R})$ are expressed in high-rostral to low-caudal gradients in the cortical plate (arrow indicates the regions with high level of expression). Id $2(\mathbf{O}, \mathbf{S})$ and $L$ mo4 $(\boldsymbol{P}, \boldsymbol{T})$ both show high expression in the rostral (arrow) and caudal (arrowhead) parts of the cortex and their expression level drops in the middle part. These general patterns of differential expression are not altered in Olig $3^{\text {rre/ }^{+}} ; G b \times 2^{N / C}$ embryos. Scale bars, $1 \mathrm{~mm}$. $\boldsymbol{U}, \boldsymbol{V}$, Persistent defects of thalamus and TCA projections in Gbx2 cko mice at P21. (resyl violet staining of coronal sections through the forebrain. Medial is to the left. In the Gbx2 cko brain, the thalamus is disorganized and reduced in size. TCA projections (tca) still appear to be absent ( $\boldsymbol{V}$, arrowhead), whereas corticofugal axons (cp; cerebral peduncle) seem to be intact. Scale bars, $1 \mathrm{~mm}$.

$R O R \beta$-positive layer 4 in the barrel field of $\mathrm{S} 1 \mathrm{~S} 1 \mathrm{BF})$ was dramatically reduced (Fig. $8 G$ ), whereas the gap between strong $R O R \beta$ expression in the hindlimb region (S1HL) and S1BF (Fig. $8 B$, near arrow) was not detected in the mutant cortex (Fig. $8 G$ ).
Tangential sections through layer 4 of the Gbx2 cko cortex showed severely disorganized pattern of $R O R \beta$ expression, reflecting the blurred borders of its expression domains and the thinning of layer 4 (Fig. 9G,H). 




Figure 8. Altered gene expression patterns and lack of distinct areal boundaries in Gbx2 cko cortex at P8. In situ hybridization on coronal sections of Olig $3^{\mathrm{Cre} /+} ; \mathrm{Gbx}^{\mathrm{C} / \mathrm{C}}$ pups and their littermate controls. Medial is to the left. The left-most column represents the rostral level that includes both the motor and $\mathrm{S1}$ (forelimb) areas, and the right-most column includes sections at the level of V1 and A1. Expression of $R O R \beta(\boldsymbol{A}-\boldsymbol{E}$ in controls, $\boldsymbol{F}-\boldsymbol{J}$ in cko), $\mathbf{L}$ mo4 $(\boldsymbol{K}-\mathbf{O}$ in controls, $\boldsymbol{P}-\boldsymbol{T}$ in cko) and $(d h 8$ ( $\boldsymbol{U}-\boldsymbol{Y}$ in controls, $\boldsymbol{Z}-\boldsymbol{d}$ in cko) was compared between the cko and control brains. For each genotype, images in the same column $(\boldsymbol{A}, \boldsymbol{K}, \boldsymbol{U} ; \boldsymbol{B}, \boldsymbol{L}, \boldsymbol{V} ; \boldsymbol{C}, \boldsymbol{M}, \boldsymbol{W} ; \boldsymbol{D}, \boldsymbol{N}, \boldsymbol{X} ; \boldsymbol{E}, \boldsymbol{O}, \boldsymbol{Y} ; \boldsymbol{F}, \boldsymbol{P}, \boldsymbol{Z} ; \boldsymbol{G}, \mathbf{Q}, \boldsymbol{a} ; \boldsymbol{H}, \boldsymbol{R}, \boldsymbol{b} ; \boldsymbol{I}, \boldsymbol{S}, \boldsymbol{C} ; \boldsymbol{J}, \boldsymbol{I}, \boldsymbol{d})$ are serially adjacent sections taken from the same brain and thus are directly comparable. Black arrows show normal area boundaries, whereas red arrows show the lack of distinct gene expression boundaries found in Gbx2 cko brains. Scale bars, $1 \mathrm{~mm}$.

Lmo4 showed largely complementary expression patterns to that of $R O R \beta$. In the control motor cortex, Lmo4 was strong not only in layer 4 but also in layers $2,3,5$, and 6 (Fig. $8 K$ ). In the adjacent $\mathrm{S} 1$ (forelimb, lip, and jaw areas), which is located lateral to the motor area, $L m o 4$ was faint and restricted to layers 4 and 6 (Fig. 8K). At more caudal levels containing S1BF, Lmo4 expression was almost undetectable except in layer 6, forming a sharp medial border of S1BF (Fig. $8 L-N$ ). At the caudal-most level, expression of Lmo4 in layer 4 was excluded from the primary sensory areas SIBF and V1, clearly demarcating their borders (Fig. $8 \mathrm{~N}, \mathrm{O}$ ). In $\mathrm{Gb} \times 2$ cko mice, $L m o 4$ was ectopically expressed in layer 4 of S1BF and V1, which made the primary sensory areas resemble the adjacent, higher-order sensory areas (Fig. 8Q-T). At more rostral levels, we found the motor area showed reduced expression of $L m o 4$, making the distinction from the adjacent $\mathrm{S} 1$ less clear (Fig. 8P).

Cdh 8 expression in layers 5 and 6 was broad across the entire neocortex, whereas its expression in layers 2,3 , and 4 was gener- ally higher medially than laterally (Fig. $8 U-Y$ ). We found that layer 4 of S1 and V1 shows specifically low expression of $C d h 8$, clearly delineating their boundaries (Fig. $8 U-Y$ ), which was also confirmed on sagittal sections (Figs. $5 I, J, 9 E$ ). In $G b \times 2$ cko cortex, this Cdh8-low "hollows" in V1 was no longer detectable and the pattern of $C d h 8$ expression was indistinguishable between the putative $\mathrm{V} 1$ and its surrounding areas (Figs. $8 c, d, 9 F$ ).

In summary, $G b \times 2$ cko mice showed altered patterns of laminar and areal gene expression patterns in the neocortex at the end of the first postnatal week. As a result, discrete areal boundaries, particularly the boundaries of primary sensory areas, were much less clearly defined. These results demonstrate the requirement of TCA projections in the formation of distinct gene expression patterns across neocortical areas.

\section{Discussion}

In this study, altering the size and cell number in the thalamic dLG nucleus resulted in corresponding changes in the size of its 


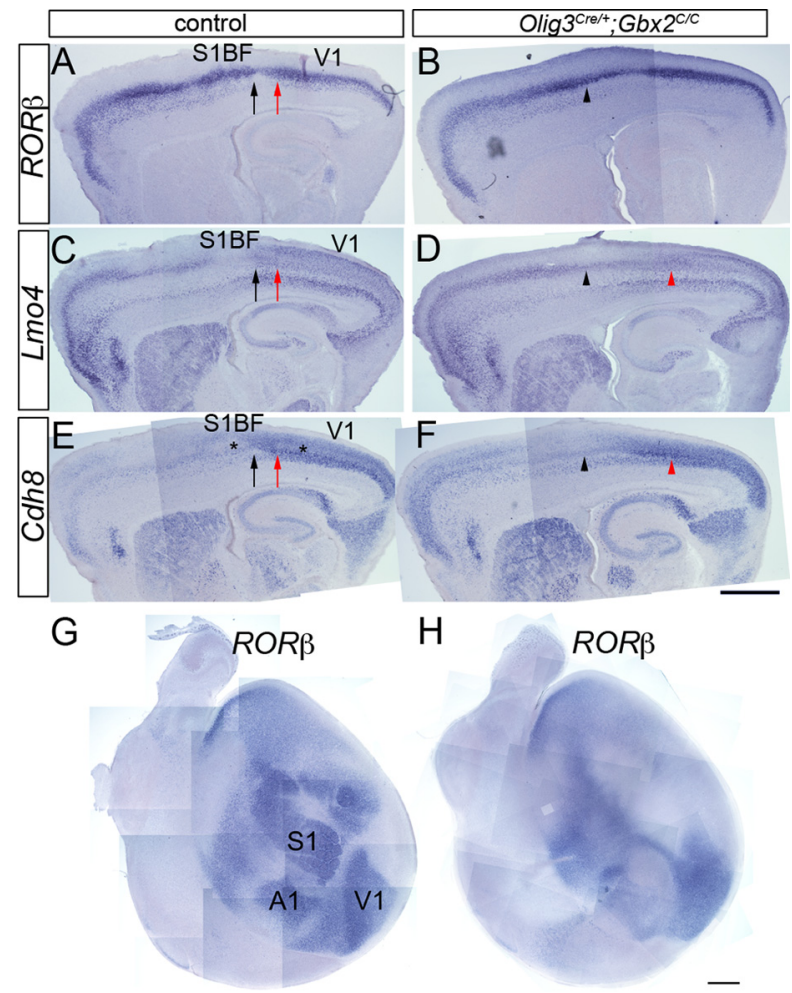

Figure 9. Sagittal and tangential sections of P8 Gbx2 cko cortex. $\boldsymbol{A}-\boldsymbol{F}$, Lack of discrete areal gene expression boundaries on sagittal sections of $\mathrm{P} 8 \mathrm{Gbx} 2 \mathrm{ck}$ cortex. In situ hybridization of

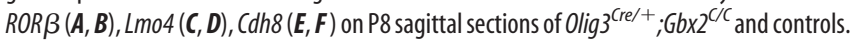
Rostral is to the left. $\boldsymbol{A}, \boldsymbol{C}$, and $\boldsymbol{E}$ and $\boldsymbol{B}, \boldsymbol{D}$, and $\boldsymbol{F}$ are serially adjacent sets of sections taken from the same brain. Rostral border of $\mathrm{V} 1$ and caudal border of $\mathrm{S} 1$ in control cortex are shown by red and black arrows, respectively. The Cdh8-low "hollow" in layer 4 indicated the location of V1 and S1 (shown by asterisk in $\boldsymbol{E}$ ). In Gbx2 cko mice, areal gene expression border is less clear. $R O R \beta$ expression in layer 4 is much less robust in S1BF of $G b \times 2$ cko cortex ( $\boldsymbol{B}$, black arrowhead), whereas $L m 04$ is ectopically expressed in layer 4 of both $V 1(\boldsymbol{D}$, red arrowhead) and S1BF ( $\boldsymbol{D}$, black arrowhead). (dh8-low hollows are less obvious in $G$ bx2 cko cortex ( $\boldsymbol{F}$, arrowheads). Scale bar, $500 \mu \mathrm{m}$. $\mathbf{G}, \boldsymbol{H}$, Lack of discrete borders of $R O R \beta$ expression in layer 4 of $G b x 2$ cko cortex at $P 8$. In situ hybridization of $R O R \beta$ on tangential sections through layer 4 . Scale bar, $1 \mathrm{~mm}$. target area, V1, at postnatal stages. In addition, genetic removal of a majority of TCAs in the neocortex prevented the formation of discrete gene expression boundaries between areas. These results collectively demonstrate both the sufficiency and requirement of TCAs in defining neocortical area boundaries.

Previous studies addressing the roles of TCAs in the formation of neocortical areas relied largely on postnatal manipulations of afferent innervation of the cortex. For example, surgical ablation of the thalamus in neonatal rats and mice resulted in the lack of characteristic barrel-like histology and lack of expression of the transgene H-2Z1 in S1 (Wise and Jones, 1978; Windrem and Finlay, 1991; Gitton et al., 1999). Transplantation of late embryonic tissue of the rat occipital cortex to the parietal cortex of the neonatal host brain resulted in the barrel-like morphological features in the graft (Schlaggar and O'Leary, 1991), supporting the idea that thalamic afferents have influence on the areal fate of the neocortical cells. In these studies, manipulations were done on the tissue after TCAs had started the invasion of the cortical plate. Therefore, it was not clear whether TCAs are required for the initial establishment of areal features or their maintenance. Bilateral eye removal in monkey fetuses before the arrival of TCAs at the occipital cortex resulted in partial replacement of the primary visual area with an area in which layer 4 was much thinner; designated as area 18 (Dehay et al., 1989, 1991,1996) and "area X" (Rakic, 1988, 1991). Although these studies demonstrate the requirement of the afferent input in characteristic cytoarchitecture of the primary visual cortex, the indirect nature of afferent manipulations and the difficulty of in utero surgeries on primate fetuses prevented further elucidation of when and how the geniculocortical axons affect V1 formation.

Mutant mouse lines that lack TCA projections to the neocortex did not show gross changes of regional gene expression patterns in the neocortex (Miyashita-Lin et al., 1999; Nakagawa et al., 1999). Furthermore, in mice where subcortical defects caused a shift in the topographic projections of TCAs in the neocortex, regional gene expression in the cortical plate was not affected at late embryonic stages (Garel et al., 2002). These studies indicated the sufficiency of intrinsic patterning mechanisms in regional differentiation of the neocortex, which is independent of thalamic afferents. However, all of these mutant mice died at birth, preventing the analysis of detailed area-specific and layer-specific patterns of gene expression that become evident only postnatally. A more recent study reported that gene expression patterns in postnatal cortex look grossly normal in mice lacking both TCAs and corticofugal axons (Zhou et al., 2010), leading the authors to propose that arealization in early postnatal neocortex is independent of TCAs. Furthermore, grafting of embryonic stem cell-derived cortical neurons harboring molecular signatures of the visual area established subcortical and intracortical connectivity characteristic of visual cortical neurons even when these cells were grafted into the frontal cortex, again indicating the sufficiency of intrinsic mechanisms in the specification of cortical area identity (Gaspard et al., 2008). Thus, it has remained elusive whether or how TCAs regulate the early establishment of area identity.

In this study, we genetically altered early thalamic patterning and TCA path-
Figure 10. Schematic summary of the study. $\boldsymbol{A}$, Normal thalamocortical system. Specific TCA inputs from individual thalamic nuclei induce area-specific gene expression patterns in their target regions of the neocortex. Visual (dLG to V1) and somatosensory (VP to S1) are shown as examples. These specific inputs act on the immature cortex that is patterned by intrinsic mechanisms (represented in gradients of gray color). $\boldsymbol{B}$, In severe deficiency of TCA inputs in thalamus-specific Gbx2 mutant mice, patterns of gene expression in the putative V1 and $S 1$ resembled those in the nearby nonprimary sensory areas, resulting in the lack of distinct boundaries. $C, D$, When the size of the $\mathrm{dLG}$ nucleus was increased $(\boldsymbol{C}$ ) or decreased $(\boldsymbol{D})$ as a result of manipulating Shh signaling in thalamic progenitor cells, geniculocortical projections were expanded or shrunken, and the V1 size was also altered accordingly. As a result, the gap between $\$ 1$ and V1 was narrowed or widened. 
finding without affecting the intrinsic patterning mechanisms within the cortex. When dLG and its cortical projections were expanded or shrunken, discrete area boundaries still formed but their positions shifted according to the altered size of the geniculocortical projections (Fig. $10 A, C, D$ ). The LP nucleus, which normally projects to higher-order visual areas, showed reciprocal size changes to those of dLG. When the entire TCA projections were severely disrupted regardless of their nuclear origin, the postnatal cortex no longer exhibited distinct gene expression patterns that delineate boundaries of primary sensory areas (Fig. $10 B)$. The disruption was most pronounced in the nascent primary sensory areas, where layer 4 was significantly affected both in gene expression patterns and in its thickness. These results indicate that TCAs from principal sensory thalamic nuclei provide specific information to instruct the target cortical regions to take on the fate of primary sensory areas, which would otherwise become higher order sensory areas as a default fate. The gross patterns of gene expression that we observed in $G b \times 2$ cko neocortex were still partially reminiscent of those in the normal mice. This provides the first detailed picture of the default state of area specification, which is set up by early intrinsic pattering and nonthalamic afferents that are intact in $G b \times 2$ cko mice.

It is currently unknown which populations of cortical cells are directly influenced by TCAs during the formation of areas. A likely scenario is that immature cortical plate neurons are exposed to molecules that are provided by the incoming TCAs and undergo dynamic changes in gene expression, which are evident by comparing the patterns between E17.5 (Figs. 2, 7) and P8 (Figs. 4, 8).

The gradients of gene expression in embryonic cortical plate are smooth, and their subtle changes could be difficult to detect. Therefore, although we did not find gross changes in gene expression in the cortical plate at E17.5 when TCAs were altered (Figs. 2, 7 ), this result does not completely exclude the possibility that TCAs have a role in embryonic cortex.

Because of the reduced thickness of layer 4 in S1BF, it is possible that TCAs have influence on the neuronal number in layer 4 of the primary sensory areas. We did not observe significant increase in cell death in layer 4 at E17.5 or P8 in Gbx2 cko mice (data not shown), which suggests that generation of layer 4 neurons might be under the regulation of TCAs. Therefore, it would be worth investigating the roles of TCAs in embryonic cortical development, and our model mice would be ideal for this purpose because of the early and specific manipulations of TCAs.

Currently, little is known about the cellular and molecular mechanisms responsible for the roles of TCAs in early neocortical development. Results of our study indicated that specific factors produced by principle sensory thalamic nuclei induce the characteristic gene expression and cytoarchitecture of primary sensory areas, and without the TCA afferent, the neocortical areas resemble adjacent, higher-order sensory areas as a default state. Our transgenic mouse models will be useful in future studies to identify potential candidate molecules and reveal the cellular and molecular mechanisms of area formation in the neocortex.

\section{References}

Bluske KK, Vue TY, Kawakami Y, Taketo MM, Yoshikawa K, Johnson JE, Nakagawa Y (2012) beta-catenin signaling specifies progenitor cell identity in parallel with shh signaling in the developing mammalian thalamus. Development 139:2692-2702. CrossRef Medline

Borello U, Pierani A (2010) Patterning the cerebral cortex: traveling with morphogens. Curr Opin Genet Dev 20:408-415. CrossRef Medline

Bulfone A, Puelles L, Porteus MH, Frohman MA, Martin GR, Rubenstein JL (1993) Spatially restricted expression of Dlx-1, Dlx-2 (Tes-1),
Gbx-2, and Wnt-3 in the embryonic day 12.5 mouse forebrain defines potential transverse and longitudinal segmental boundaries. J Neurosci 13:3155-3172. Medline

Chen L, Guo Q, Li JY (2009) Transcription factor Gbx2 acts cellnonautonomously to regulate the formation of lineage-restriction boundaries of the thalamus. Development 136:1317-1326. CrossRef Medline

Dehay C, Horsburgh G, Berland M, Killackey H, Kennedy H (1989) Maturation and connectivity of the visual cortex in monkey is altered by prenatal removal of retinal input. Nature 337:265-267. CrossRef Medline

Dehay C, Horsburgh G, Berland M, Killackey H, Kennedy H (1991) The effects of bilateral enucleation in the primate fetus on the parcellation of visual cortex. Brain Res Dev Brain Res 62:137-141. CrossRef Medline

Dehay C, Giroud P, Berland M, Killackey H, Kennedy H (1996) Contribution of thalamic input to the specification of cytoarchitectonic cortical fields in the primate: effects of bilateral enucleation in the fetal monkey on the boundaries, dimensions, and gyrification of striate and extrastriate cortex. J Comp Neurol 367:70 -89. CrossRef Medline

Garel S, Yun K, Grosschedl R, Rubenstein JL (2002) The early topography of thalamocortical projections is shifted in Ebf1 and Dlx1/2 mutant mice. Development 129:5621-5634. CrossRef Medline

Gaspard N, Bouschet T, Hourez R, Dimidschstein J, Naeije G, van den Ameele J, Espuny-Camacho I, Herpoel A, Passante L, Schiffmann SN, Gaillard A, Vanderhaeghen P (2008) An intrinsic mechanism of corticogenesis from embryonic stem cells. Nature 455:351-357. CrossRef Medline

Gitton Y, Cohen-Tannoudji M, Wassef M (1999) Role of thalamic axons in the expression of $\mathrm{H}-2 \mathrm{Zl}$, a mouse somatosensory cortex specific marker. Cereb Cortex 9:611-620. CrossRef Medline

Hevner RF, Miyashita-Lin E, Rubenstein JL (2002) Cortical and thalamic axon pathfinding defects in Tbr1, Gbx2, and Pax6 mutant mice: evidence that cortical and thalamic axons interact and guide each other. J Comp Neurol 447:8-17. CrossRef Medline

Hoch RV, Rubenstein JL, Pleasure S (2009) Genes and signaling events that establish regional patterning of the mammalian forebrain. Semin Cell Dev Biol 20:378-386. CrossRef Medline

Jeong J, Mao J, Tenzen T, Kottmann AH, McMahon AP (2004) Hedgehog signaling in the neural crest cells regulates the patterning and growth of facial primordia. Genes Dev 18:937-951. CrossRef Medline

Jeong Y, Dolson DK, Waclaw RR, Matise MP, Sussel L, Campbell K, Kaestner KH, Epstein DJ (2011) Spatial and temporal requirements for sonic hedgehog in the regulation of thalamic interneuron identity. Development 138:531-541. CrossRef Medline

Jones EG, Rubenstein JL (2004) Expression of regulatory genes during differentiation of thalamic nuclei in mouse and monkey. J Comp Neurol 477:55-80. CrossRef Medline

Lebrand C, Cases O, Adelbrecht C, Doye A, Alvarez C, El Mestikawy S, Seif I, Gaspar P (1996) Transient uptake and storage of serotonin in developing thalamic neurons. Neuron 17:823-835. CrossRef Medline

Lewis PM, Dunn MP, McMahon JA, Logan M, Martin JF, St-Jacques B, McMahon AP (2001) Cholesterol modification of sonic hedgehog is required for long-range signaling activity and effective modulation of signaling by Ptc1. Cell 105:599-612. CrossRef Medline

Li JY, Lao Z, Joyner AL (2002) Changing requirements for Gbx2 in development of the cerebellum and maintenance of the mid/hindbrain organizer. Neuron 36:31-43. CrossRef Medline

Li K, Zhang J, Li JY (2012) Gbx2 plays an essential but transient role in the formation of thalamic nuclei. PLoS One, 7:e47111. CrossRef

Liu Z, Li H, Hu X, Yu L, Liu H, Han R, Colella R, Mower GD, Chen Y, Qiu M (2008) Control of precerebellar neuron development by Olig3 bHLH transcription factor. J Neurosci 28:10124-10133. CrossRef Medline

Madisen L, Zwingman TA, Sunkin SM, Oh SW, Zariwala HA, Gu H, Ng LL, Palmiter RD, Hawrylycz MJ, Jones AR, Lein ES, Zeng H (2010) A robust and high-throughput Cre reporting and characterization system for the whole mouse brain. Nat Neurosci 13:133-140. CrossRef Medline

Miyashita-Lin EM, Hevner R, Wassarman KM, Martinez S, Rubenstein JL (1999) Early neocortical regionalization in the absence of thalamic innervation. Science 285:906-909. CrossRef Medline

Nakagawa Y, O'Leary DD (2001) Combinatorial expression patterns of LIM-homeodomain and other regulatory genes parcellate developing thalamus. J Neurosci 21:2711-2725. Medline

Nakagawa Y, Shimogori T (2012) Diversity of thalamic progenitor cells and postmitotic neurons. Eur J Neurosci 35:1554-1562. CrossRef Medline 
Nakagawa Y, Johnson JE, O'Leary DD (1999) Graded and areal expression patterns of regulatory genes and cadherins in embryonic neocortex independent of thalamocortical input. J Neurosci 19:10877-10885. Medline

Nakagawa Y, O'Leary DD (2003) Dynamic patterned expression of orphan nuclear receptor genes $\operatorname{ROR} \alpha$ and $\operatorname{ROR} \beta$ in developing mouse forebrain. Dev Neurosci 25:233-244. CrossRef Medline

Nakashiba T, Nishimura S, Ikeda T, Itohara S (2002) Complementary expression and neurite outgrowth activity of netrin-G subfamily members. Mech Dev 111:47-60. CrossRef Medline

O'Leary DD, Chou SJ, Sahara S (2007) Area patterning of the mammalian cortex. Neuron 56:252-269. CrossRef Medline

Rakic P (1988) Specification of cerebral cortical areas. Science 241:170-176. CrossRef Medline

Rakic P, Suner I, Williams RW (1991) A novel cytoarchitectonic area induced experimentally within the primate visual cortex. Proc Natl Acad Sci U S A, 88:2083-2087. CrossRef

Rakic P, Ayoub AE, Breunig JJ, Dominguez MH (2009) Decision by division: making cortical maps. Trends Neurosci 32:291-301. CrossRef Medline

Sansom SN, Livesey FJ (2009) Gradients in the brain: the control of the development of form and function in the cerebral cortex. Cold Spring Harb Perspect Biol, 1:a002519. CrossRef Medline

Schaeren-Wiemers N, Andr é E, Kapfhammer JP, Becker-Andre M (1997) The expression pattern of the orphan nuclear receptor $\operatorname{ROR} \beta$ in the developing and adult rat nervous system suggests a role in the processing of sensory information and in circadian rhythm. Eur J Neurosci 9:2687-2701. CrossRef Medline

Schlaggar BL, O'Leary DD (1991) Potential of visual cortex to develop an array of functional units unique to somatosensory cortex. Science 252: 1556-1560. CrossRef Medline
Scholpp S, Lumsden A (2010) Building a bridal chamber: development of the thalamus. Trends Neurosci 33:373-380. CrossRef Medline

Storm R, Cholewa-Waclaw J, Reuter K, Bröhl D, Sieber M, Treier M, Müller T, Birchmeier C (2009) The bHLH transcription factor Olig3 marks the dorsal neuroepithelium of the hindbrain and is essential for the development of brainstem nuclei. Development 136:295-305. CrossRef Medline

Szab ó NE, Zhao T, Zhou X, Alvarez-Bolado G (2009) The role of Sonic hedgehog of neural origin in thalamic differentiation in the mouse. J Neurosci 29:2453-2466. CrossRef Medline

Vieira C, Pombero A, García-Lopez R, Gimeno L, Echevarria D, Martnez S (2010) Molecular mechanisms controlling brain development: an overview of neuroepithelial secondary organizers. Int J Dev Biol 54:7-20. CrossRef Medline

Vue TY, Aaker J, Taniguchi A, Kazemzadeh C, Skidmore JM, Martin DM, Martin JF, Treier M, Nakagawa Y (2007) Characterization of progenitor domains in the developing mouse thalamus. J Comp Neurol 505: 73-91. CrossRef Medline

Vue TY, Bluske K, Alishahi A, Yang LL, Koyano-Nakagawa N, Novitch B, Nakagawa Y (2009) Sonic hedgehog signaling controls thalamic progenitor identity and nuclei specification in mice. J Neurosci 29: 4484-4497. CrossRef Medline

Windrem MS, Finlay BL (1991) Thalamic ablations and neocortical development: alterations of cortical cytoarchitecture and cell number. Cereb Cortex 1:230-240. CrossRef Medline

Wise SP, Jones EG (1978) Developmental studies of thalamocortical and commissural connections in the rat somatic sensory cortex. J Comp Neurol 178:187-208. CrossRef Medline

Zhou L, Gall D, Qu Y, Prigogine C, Cheron G, Tissir F, Schiffmann SN, Goffinet AM (2010) Maturation of "neocortex isole" in vivo in mice. J Neurosci 30:7928-7939. CrossRef Medline 